\title{
Synthesis, reactions and applications of pyranotriazolopyrimidines
}

\author{
Ashraf Hassan Fekry Abd El-Wahab a,b,*, Ibrahim Ali Radini a and Hany Mostafa Mohamed a,b \\ a Chemistry Department, Faculty of Science, Jazan University, 2097, Jazan, Saudi Arabia \\ b Chemistry Department, Faculty of Science, Al-Azhar University, 11884, Nasr City, Cairo, Egypt \\ *Corresponding author at: Chemistry Department, Faculty of Science, Jazan University, 2097, Jazan, Saudi Arabia. \\ Tel.: +966.054.0963753. Fax: +966.017.3230028. E-mail address: ash abdelwahab@yahoo.com (A.H.F.A. El-Wahab).
}

\section{REVIEW INFORMATION}

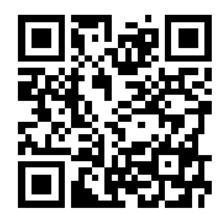

DOI: $10.5155 /$ eurjchem.5.4.681-694.1087

Received: 30 April 2014

Received in revised form: 27 May 2014

Accepted: 27 May 2014

Online: 31 December 2014

\section{KEYWORDS}

\section{Naphthols}

Pyrimidine

Biological activity

Pyranopyrimidines

$\alpha$-Cyanocinnamonitriles

Carboxylic acid derivatives

\section{Introduction}

Pyran derivatives have attracted a great deal of interest owing to their antimicrobial activity [1-7], inhibition of influenza, virus sialidase [8], mutagenic activity [9], activity as antiviral [10], anti-proliferaction agents [11], sex pheromones [12], antitumor [13] and anti-inflammatory agents [14].

The condensation of a ring of 1,2,4-triazole and another one of pyrimidine gives rise to the formation of bicyclic heterocycles known as 1,2,4-triazolopyrimidines. Four different possibilities exist for the relative orientation of both rings, so four different isomeric families of compounds are defined: 1,2,4-triazolo[1,5-a]pyrimidine (I), 1,2,4-triazolo[1,5-c]pyrimidine (II), 1,2,4-triazolo[4,3-a]pyrimidine (III) and 1,2,4triazolo[4,3-c]pyrimidine (V) (Figure 1).

Among these isomeric families of compounds, 1,2,4triazolo[1,5- $a]$-pyrimidine derivatives are thermodynamically more stable and, thus, the most studied ones [15], a few of them being commercially available. Revisions surveying the synthesis, reactivity, spectroscopic characterization and crystallographic studies of 1,2,4-triazolo[1,5-c]-pyrimidines [16], 1,2,4-triazolo[4,3-a]pyrimidines [17] and 1,2,4-triazolo [4,3-c]pyrimidines [18] have also been published.

From the standpoint of biological activity, fused heteroaromatic systems are often of much greater interest than the constituent monocyclic compounds. Recently, 1,2,4-triazolo $[1,5-a]$ pyrimidines have aroused increasing attention from the chemical and biological view points, due to their diverse pharmacological activities, such as antitumor potency $[19,20]$, inhibition of KDR kinase [21], antifungal effect [22] and macrophage activation [23].

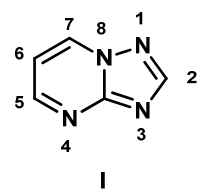

1,2,4-Triazolo[1,5-a]pyrimidine<smiles></smiles>

1,2,4-Triazolo[4,3-a]pyrimidine<smiles></smiles>

1,2,4-Triazolo[1,5-c]pyrimidine

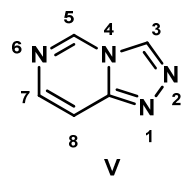

1,2,4-Triazolo[4,3-c]pyrimidine
Figure 1. Structures of triazolopyrimidines.

They have proved to be promising anticancer agents with dual mechanisms of tubulin polymerization promotion $[19,20]$ as well as anti-mycobacterial agents [24]. Some examples of 
published derivatives of 1,2,4-triazolo[1,5-a]pyrimidine with their biological activities are as following.

\section{Synthesis of pyrano triazolo pyrimidine derivatives}

\subsection{Synthesis from 6-methoxy-2-naphthol [25-27]}

Condensation of 6-methoxy-2-naphthol (1) with $\alpha$ cyanocinnamonitriles (2a-f) afforded the corresponding 2amino-4-(aryl)-7-methoxy-4H-naphtho[2, 1- $b$ ]pyran-3-carbo nitriles, 3a-c, ethoxymethylene derivatives (4a-c) was obtained by refluxing compounds 2-amino-4-(aryl)-7-methoxy- $4 H_{-}$ naphtho[2,1-b]pyran-3-carbonitriles (3a-c) with triethyl orthoformate as electrophile in the presence of acetic anhydride. Hydrazinolysis of ethoxymethylene derivatives 4a-c in ethanol, at room temperature furnished the novel 10-amino-10,11dihydro-11-imino-3-methoxy-12-(aryl)-12H-naphtho $[2,1-b]$ pyrano[2,3- $d]$ pyrimidine derivatives $\mathbf{5 a - c}$ in good yield. Reaction of aminoimino derivatives 5a-c with formic acid or triethyl ortho-formate affords the corresponding pyrano triazolo-pyrimidine derivative 6a. Also compounds 5a-c reacted with acetylchloride and or benzoyl chloride gave the corresponding 11-methoxy-2-methyl/phenyl-14-(aryl)-14Hnaphtho[2,1-b]-pyrano[2,3-e][1,2,4]triazolo[1,5-c]pyrimidines $(\mathbf{6 b}, \mathbf{c})$, while cyclo-condensation of compound 5a-c with ethyl cyanoacetate or diethyl oxalate afforded the corresponding 2cyanomethyl and 2-ethoxycarbonyl derivatives $\mathbf{6 d}$ and $\mathbf{6 e}$, respectively (Scheme 1).

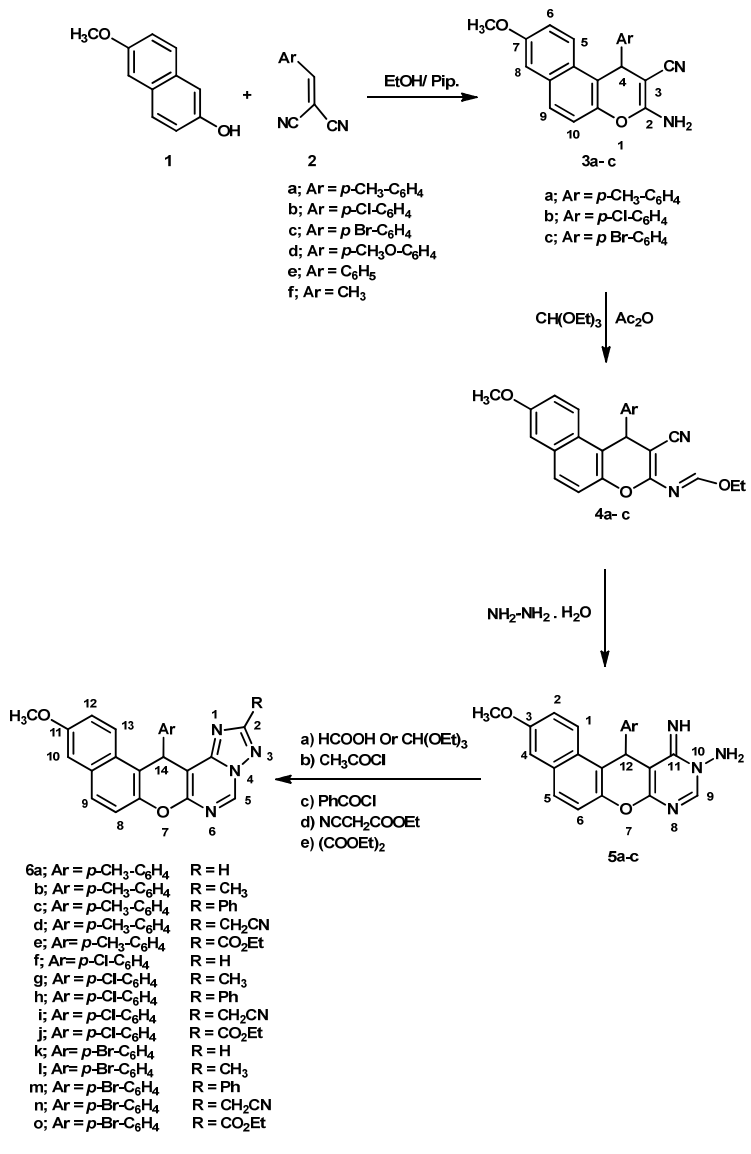

Scheme 1

Treatment of 10-amino-10,11-dihydro-11-imino-3-methoxy-12-( $p$-tolyl)-12H-naphtho[2,1-b]pyrano[2,3- $d]$ pyrimidine (5a) with two moles of ethylchloroformate in dry benzene afforded 1:2 adduct 7. Formation of compound $\mathbf{7}$ was assumed to proceed via bis(ethoxylcarbonyl) derivative [A] as intermediate, which cyclized into compound $\mathbf{7}$ with elimination of ethanol (Scheme 2).

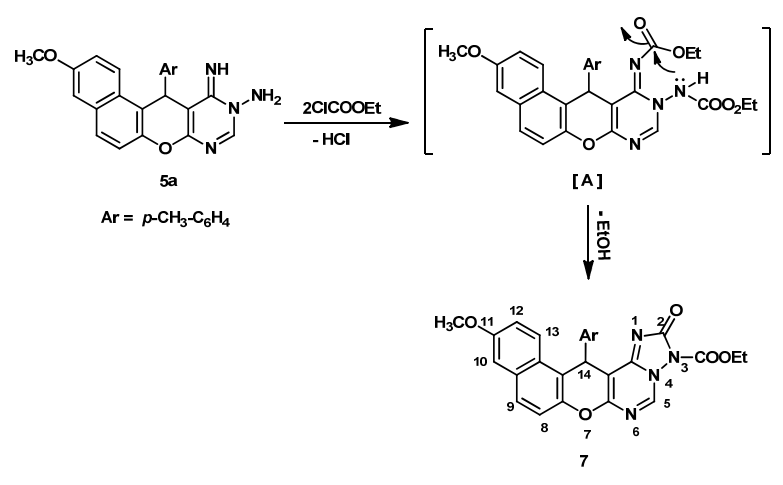

Scheme 2

While treatment of 10-amino-10,11-dihydro-11-imino-3methoxy-12-( $p$-chloro/bromophenyl)-12H-naphtho $[2,1-b]$ pyrano- $[2,3-d]$ pyrimidine $(\mathbf{5 b}, \mathbf{c})$ with ethylchloroformate in dry benzene afforded 11-methoxy-14-( $p$-chloro/bromo phenyl)-2-oxo-2 $H, 3 H, 14 H$-naphtho[2,1-b]-pyrano[3,2-e][1,2,4] triazolo[1,5-c]pyrimidines $(\mathbf{8 a}, \mathbf{b})$. Reaction of compound $\mathbf{5 b}, \mathbf{c}$ with $\mathrm{CS}_{2}$ /alc. $\mathrm{KOH}$ gave triazolo-2-thiones $(\mathbf{8 c}, \mathbf{d})$, respectively, (Scheme 3).

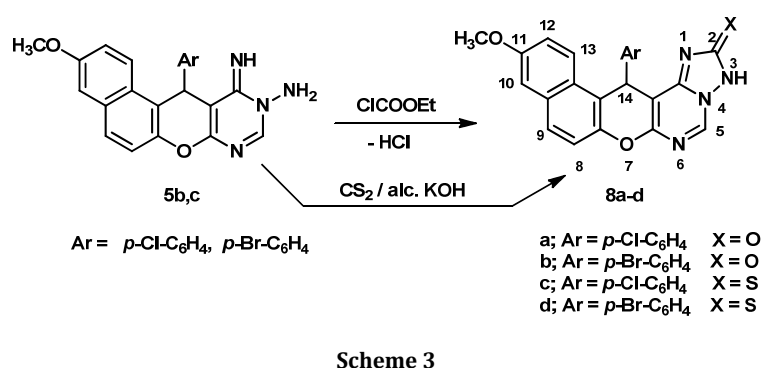

\subsection{Synthesis from 6-bromo-2-naphthol [28,29]}

Condensation of various substituted $\alpha$-cyanocinnamo nitriles 2a,c with 6-bromo-2-naphthol (10) in ethanolic piperidine afforded the corresponding 2-amino-4-(aryl)-7bromo-4H-naphtho[2,1-b]pyran-3-carbonitriles (11a-e). Treatment of compounds 11a-d with triethyl ortho-formate in acetic anhydride at reflux gave the corresponding ethoxylmethylen amino derivatives 12a-d. Hydrazinolysis of compounds 12a-d in ethanol at room temperature afforded the imino derivatives 13a-d. Interaction of compounds 13a,b with triethyl orthoformate afforded 11-bromo-14-( $p$-tolyl or $p$-methoxyphenyl)$14 H$-naphtho[1',2:5,6]pyrano[3,2-e][1,2,4]triazolo[2,3-c]pyrimidines (14a,b), respectively, (Scheme 4).

Reaction of compounds 13a,b with acetyl chloride and ethyl cyano acetate at reflux the corresponding 2-methyl-14-( $p$ tolyl or $p$-methoxyphenyl)-14H-naphtho-[2,1-b]pyrano[2,3$e][1,2,4]$ triazolo[1,5-c]pyrimidines $(\mathbf{1 4 c}, \mathbf{d})$ and 2 -acetonitrile14- ( $p$-tolyl or $p$-methoxyphenyl)-14H-naphtho[2,1- $b]$ pyrano$[2,3-e][1,2,4]$ triazolo[1,5-c]pyrimidines $\quad(\mathbf{1 4 e}, \mathbf{f})$, respectively, were formed. Reaction of compounds 13a,b with diethyl oxalate and benzoyl chloride at reflux afforded the correspondding 2-ethoxycarbonyl 14g,h and 2-phenyl 14i,j derivatives. Reaction of compound 13a with methyl or ethyl chloroformate (1 mole) in dry benzene afforded the 1:1 adduct triazol-2-one 15. Instead of the anticipated formation of the triazolo pyrimidine derivative $\mathbf{1 5}$ the reaction of compound $\mathbf{1 3 d}$ with methyl or ethyl chloroformate in dry benzene afforded 16, through nucleophilic displacement followed by spontaneous 


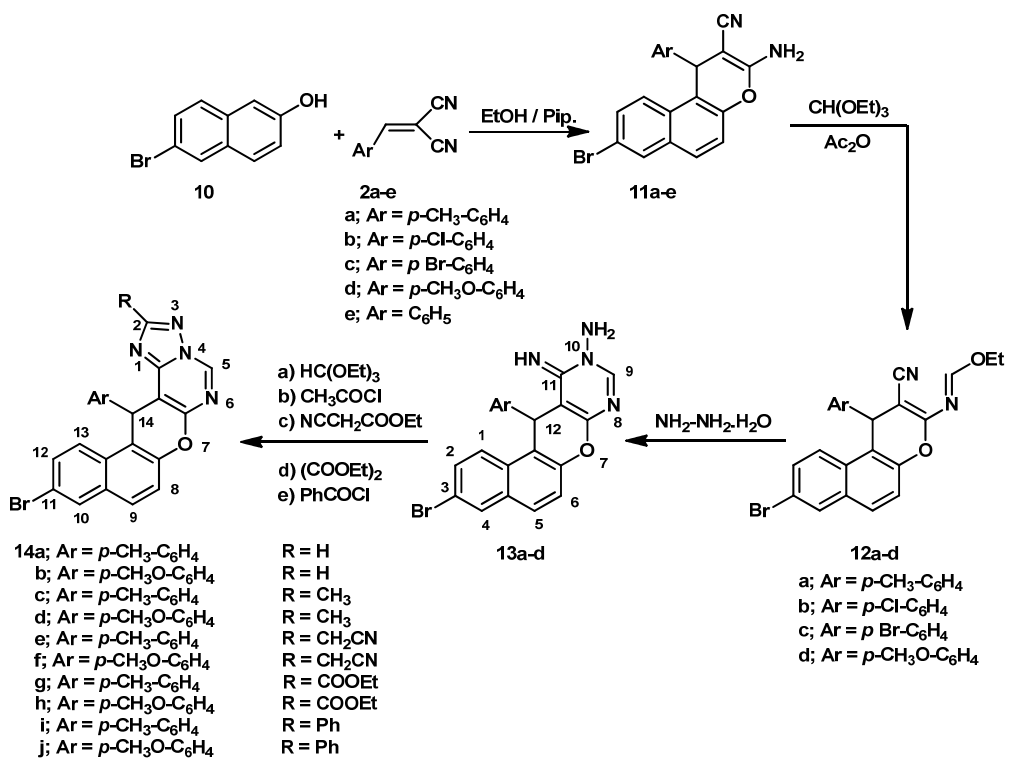

Scheme 4

hydrolysis of the ester intermediate [B] into the corresponding carbamic acid derivative 16. Interaction of compound 13a,d with benzaldehydes in dioxane/piperidine afforded $\mathbf{1 4} \mathbf{j}$ and dihydrotriazolopyrimidine derivative $\mathbf{1 7}$ and non-isolable 14i, respectively, (Scheme 5).

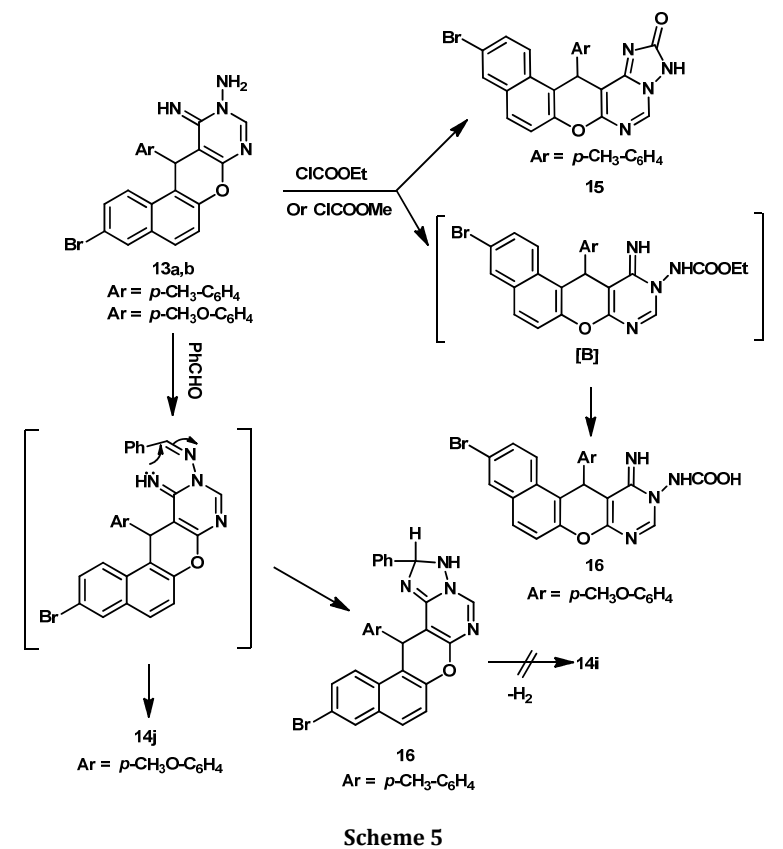

\subsection{Synthesis from 2-naphthol [30]}

Condensation of $\alpha$-cyanocinnamonitrile 2a, with 2naphthol in ethanolic piperidine afforded 2-amino-4-( $p$-tolyl)$4 H$-naphtho[2,1-b]-pyran-3-carbonitrile (18). Treatment of compound 18 with triethyl ortho-formate in acetic anhydride at reflux gave the corresponding ethoxylmethylenamino derivative 19. Hydrazinolysis of compound 19 in ethanol at room temperature afforded the imino derivative $\mathbf{2 0}$. Interaction of compound $\mathbf{2 0}$ with triethyl ortho-formate, acetyl chloride, benzoyl chloride, ethyl cyanoacetate, diethyl oxalate afforded the corresponding triazolopyrimidine derivatives 21a-e (Scheme 6).
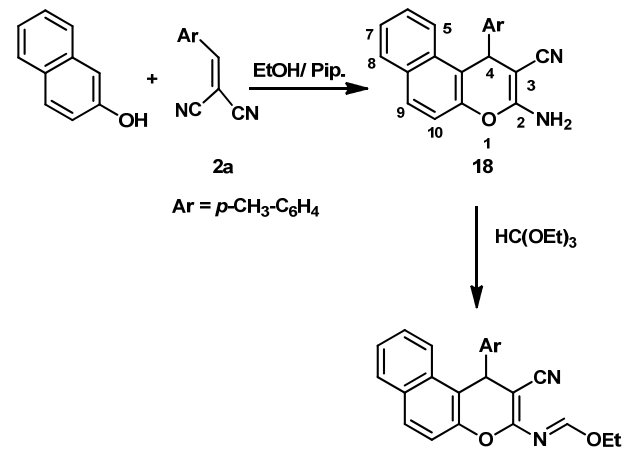

19
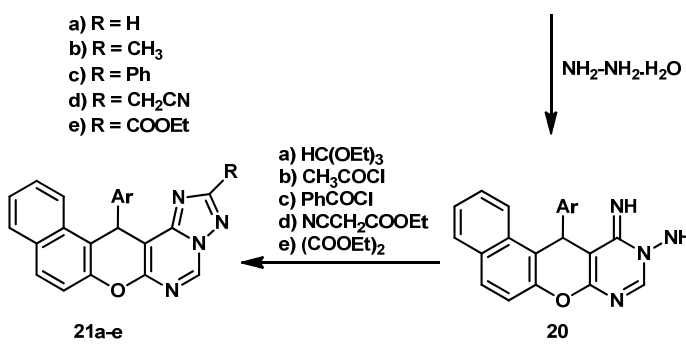

a) $\mathrm{HC}(\mathrm{OEt})_{3}$

b) $\mathrm{CH}_{3} \mathrm{COCl}$

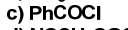

d) $\mathrm{NCCH}_{2} \mathrm{COOEt}$

e) $(\text { COOEt })_{2}$

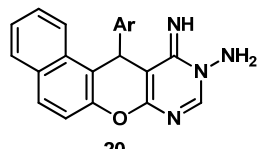

Scheme 6

\subsection{Synthesis from naphtho[2,1-b]pyrans [31]}

Reaction of 2-amino 4-aryl-3-cyano-4H-naphtho[2,1b]pyrans 18 and $\mathbf{2 2}$ with triethyl ortho-formate, triethyl orthoacetate or triethyl ortho-propionate in 1,4-dioxane, in presence amount of acetic acid under reflux to give 2-[(ethoxy alkylidene)amino-4-aryl-3-cyano-4H-naphtho-[2,1-b]pyrans 19 and 23, respectively, (Scheme 7). 


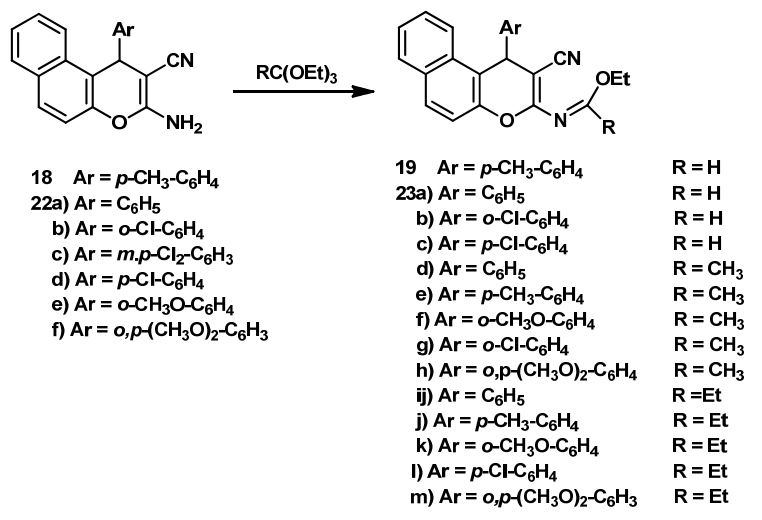

Scheme 7

The reaction of these imidates 19 and 23, with tosyl hydrazine, in toluene at reflux and few drops of acetic acid, afforded the desired key intermediate $N^{1}$-tosylamino-11-aryl1,12-dihydro-11H-naphthopyrano-[2, 3-d]pyrimidine (24) (Scheme 8).

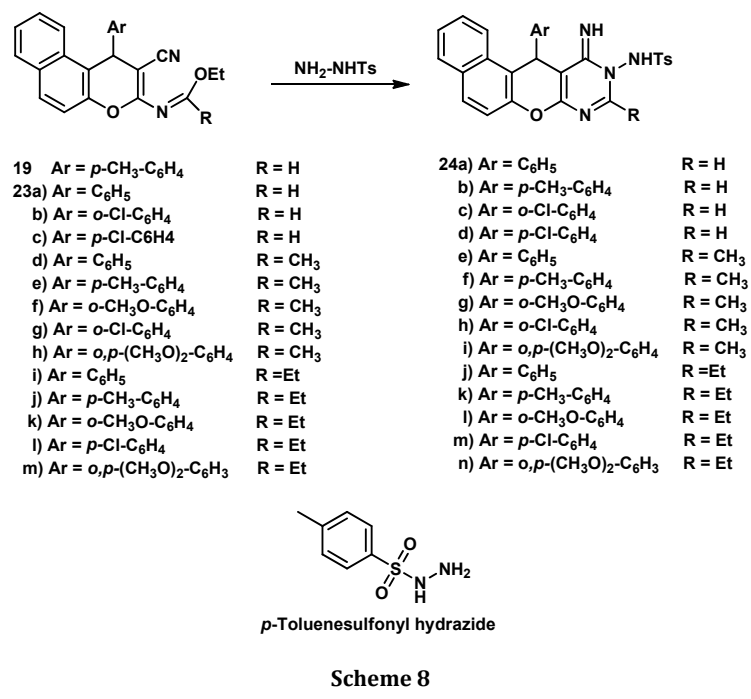

In the next step, condensed the $N^{1}$-tosylaminonaphtha pyrano[2,3- $d$ ]pyrimidines 24 , with an excess of triethyl orthoformate to give 14-aryl-14H-naphtho[2,1-b]pyrano[3,2$e][1,2,4]$ triazolo[1,5-c]yrimidines (25a-m). The formation of compounds 21a and 25a-m can be explained by asequence of events via intermediates of type [C], formed in the reaction of N1-tosylaminonaphthopyrano[2,3- $d$ ] pyrimidines $\mathbf{2 4}$ with triethyl ortho-formate, followed by spontaneous ethyl 4-methyl benzenesulfonate elimination (Scheme 9).

\subsection{Synthesis from imino ethers [32]}

Imino ethers are known to react with compounds containing $-\mathrm{NH}_{2}$ moiety such as hydrazides [33-35]. In fact imino ethers (26) possess two reactive sites, a cyano group and an imidic carbon. These groups render them susceptible to react with hydrazides under toluene reflux in the presence of few drops of acetic acid to give new compounds. As shown in (Scheme 10) two plausible pathways and different products could be expected.

i) Successive two nucleophilic additions of ( $-\mathrm{NH}_{2}$ group) on the imidic carbon and on the cyano function to yield amido pyranopyrimidines [D]. In this case hydrazides react with iminoethers 26 like hydroxylamine, primary amines [36] and tosylhydrazine [37]. The intermediate [D] can be intra- cyclisation via elimination of water to give pyrano triazolopyrimidine, 27.

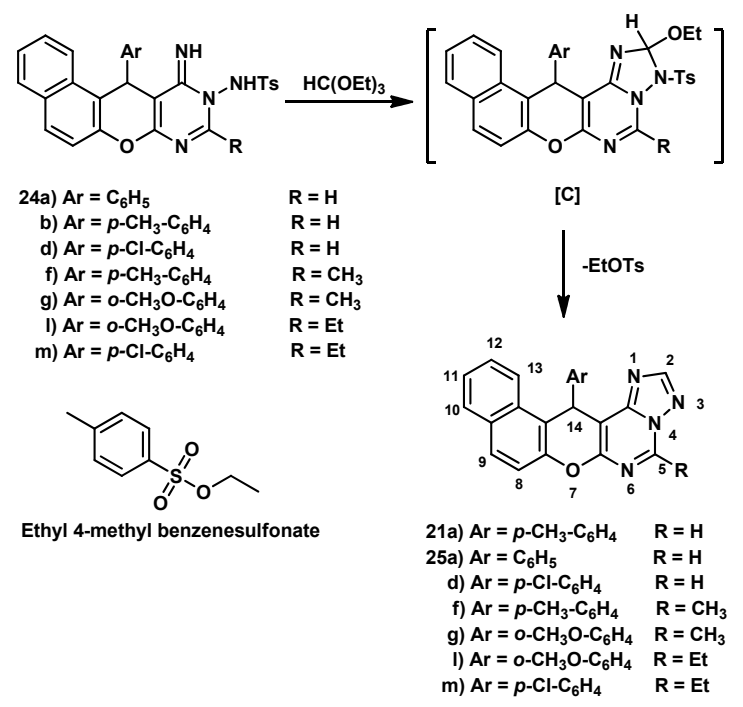

Scheme 9

ii) Successive two nucleophilic additions of two nitrogen atoms of $\mathrm{NH}_{2}-\mathrm{NH}$ moiety on the reactive sites of iminoethers $\mathbf{2 6}$ to yield pyranotriazepines $\mathbf{2 8}$ or their isomers $\mathbf{2 9}$.

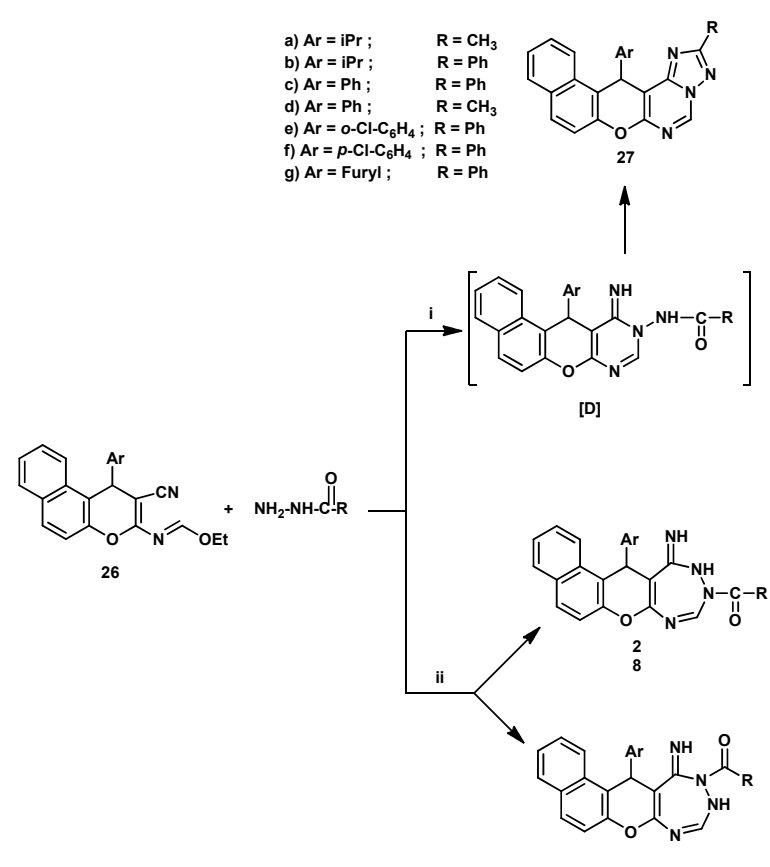

Scheme 10

\subsection{Synthesis from 4-chloro-1-naphthol [38]}

The condensation of substituted benzylidenmalonitile (2a), with 4-chloro-1-naphthol (30) in the ethanolic piperidine afforded naphthopyran 31. Treatment of 2-amino-6-chloro-4(p-tolyl )-4H-naphtho[1,2-b]pyran-3-carbonitrile (31) with triethyl ortho-formate in acetic acid at reflux gave the corresponding ethoxymethylideneamino derivative $\mathbf{3 2}$. Compound $\mathbf{3 2}$ when react with hydrazine hydrate, the naphtho[2`:1 :5,6]pyrano[2,3-d]pyrimidine derivative $\mathbf{3 3}$ was obtained, (Scheme 11). Interaction of compound 33 with triethyl orthoformate or formic acid afforded the naphtha 
$[2 ` 1 `: 5,6]$ pyrano $[3,2-e][1,2,4]$-triazolo[1,5-c]pyrimidine derivative 34a, while with acetic acid or acetyl chloride the respective 2-methyl derivative $\mathbf{3 4 b}$ was obtained. Reaction of compound 33 with chloroacetyl chloride and trichloroaceto nitrile at reflux yielding the corresponding 2-chloromethyl 34c and 2-trichloromethyl 34d derivative, respectively, while with ethyl cyanoacetate and benzoyl chloride afforded 2-cyano methyl 34e and 2-phenyl 34f derivative was obtained. Treatment of compound $\mathbf{3 3}$ with diethyl oxalate in ethanol at reflux yielded the 2-ethoxycarbonyl derivative $\mathbf{3 4 g}$, respecttively, (Scheme 11).

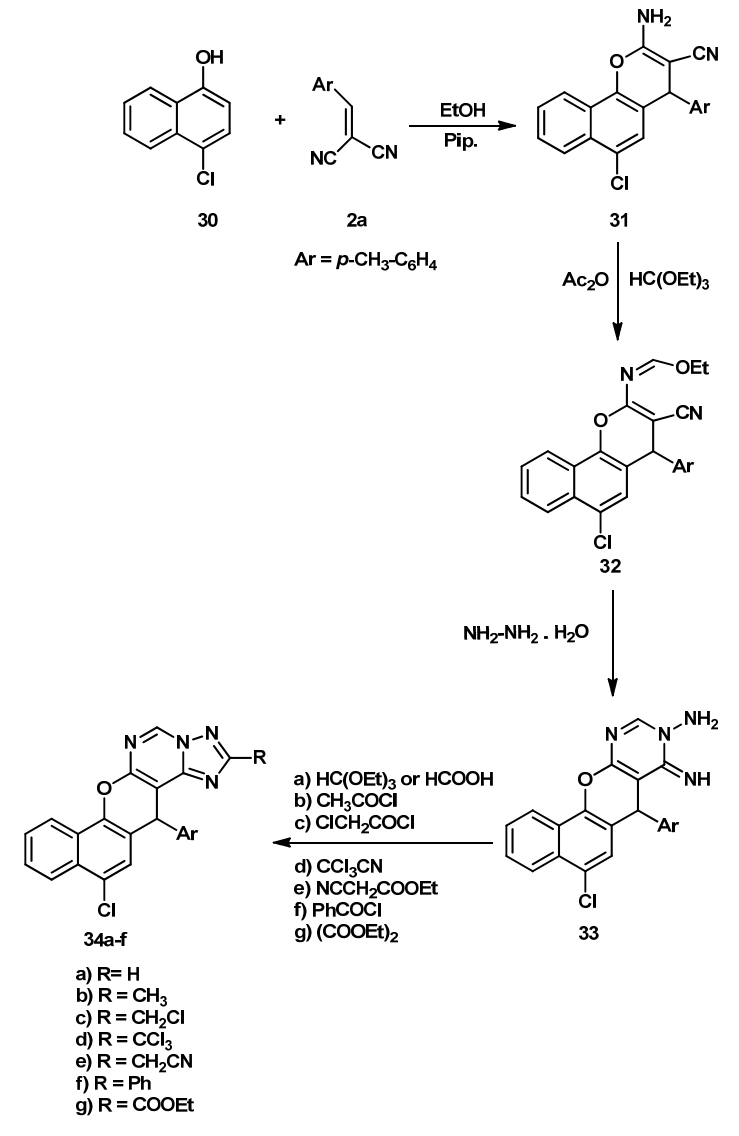

Scheme 11

Treatment of compound $\mathbf{3 3}$ with ethyl chloroformate $(1$ mole) in dry benzene afforded a 1:1 adduct 35 , while heating of compound 33 with ethyl chloroformate ( 2 moles) under reflux for $3 \mathrm{~h}$ yielded a 1:2 adduct, 36 .

The formation of compound $\mathbf{3 5}$ is assumed to proceed via interaction of compound $\mathbf{3 3}$ with ethyl chloroformate with elimination of $\mathrm{HCl}$ to yield [E] ,which then cyclizes into compound 35 with elimination of ethanol. However, compound 36 is assumed to be obtained via formation of a bis(ethoxy carbonyl) derivative [F], which cyclizes into compound $\mathbf{3 6}$ with elimination of ethanol (Scheme 12).

\subsection{Synthesis from 4H-chromene derivatives [39]}

Alkylation of 2-amino-4-(4-chlorophenyl)-7-hydroxy-4Hchromene-3- carbonitrile (37) using methyl or ethyl iodide afford 2-amino-4-(4-chlorophenyl)-7-methoxy-4H-chromene3-carbonitrile (38a), and 2-amino-4-(4-chlorophenyl)-7ethoxy-4H-chromene-3-carbonitrile (38b). Compounds 38a and $\mathbf{3 8 b}$ were reacted with triethyl orthoformate to give formimidate, 39a and 39b Interaction of compound 39a and $39 \mathbf{b}$ with equimolar amount of hydrazine hydrate in absolute ethanol at ambient temperature gave the key intermediates pyranopyrimidine derivatives $\mathbf{4 0 a}, \mathbf{b}$ Reaction of compound 40a,b with triethyl orthoformate or ethyl ethoxymethylene cyanoacetate afforded pyranotriazolopyrimidines, 41a,b While treatment of compounds 40a,b with acetic anhydride or acetoacetone gave the corresponding pyranotriazolo pyrimidines 42a,b and reaction of compounds $40 \mathbf{a}, \mathbf{b}$ with diethyl oxalate gave the corresponding pyrano triazolo pyrimidines 43a,b. Treating compounds 40a,b with equimolar amount of chloro acid chloride derivatives in dioxane containing catalytic amount of triethylamine afford triazolo derivatives 45a-d (Scheme 13).

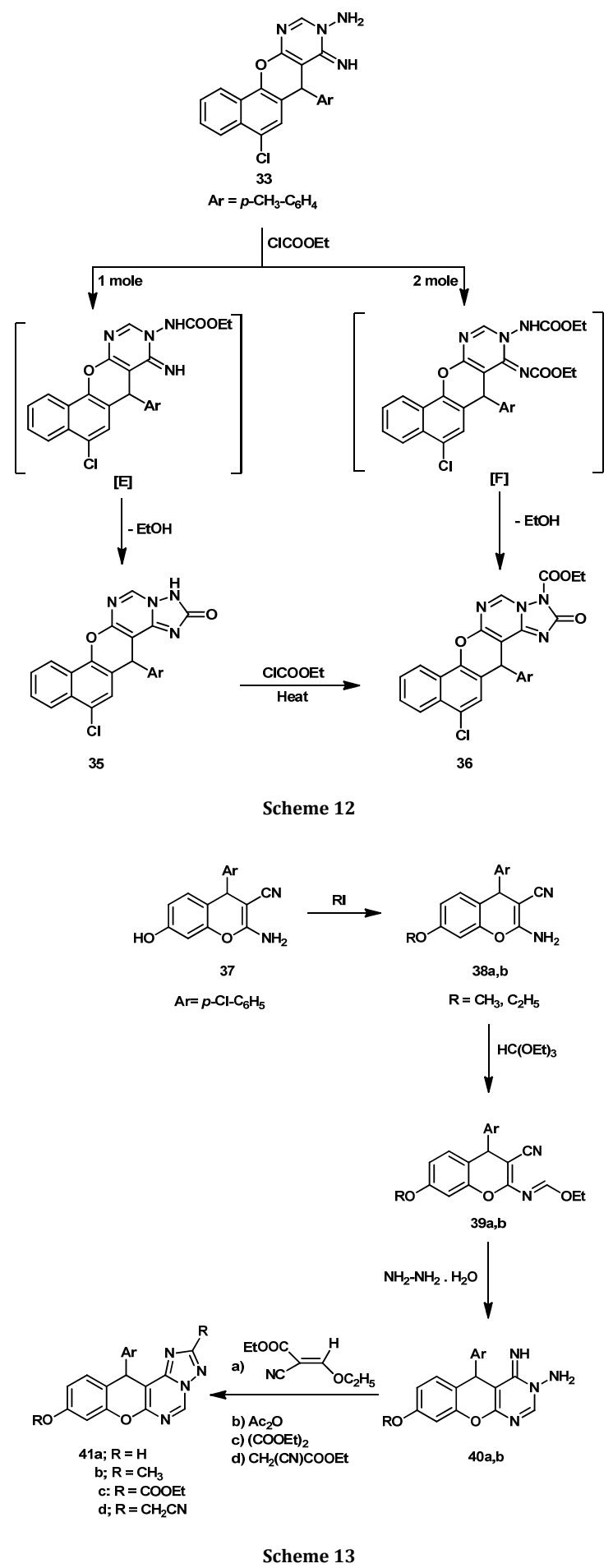


Compounds triazolo-pyrimidines $\mathbf{4 6 a}-\mathbf{f}$ were prepared from the interaction of the key intermediates 40a,b with different arylidene malononitriles $\mathbf{2}$ in the presence of piperidine under reflux in absolute ethanol (Scheme 14).

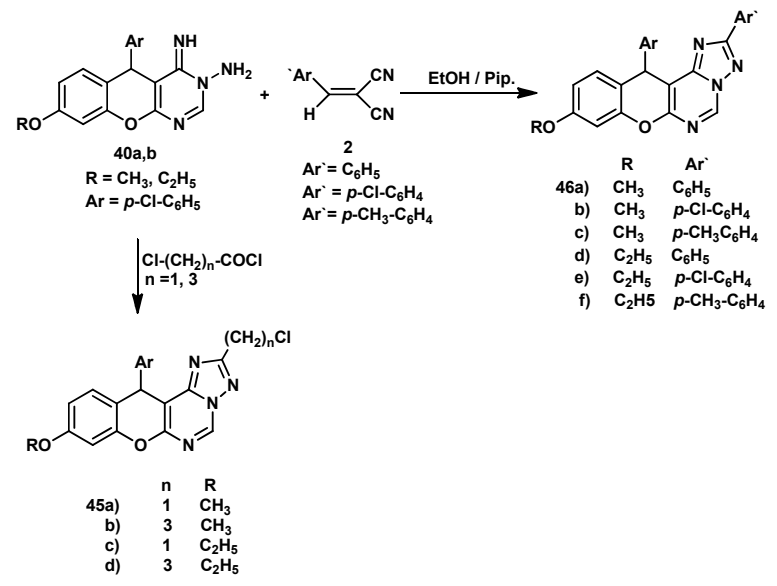

Scheme 14

\subsection{Chromeno pyrimidine [40]}

The condensation between iminoether $\mathbf{4 7}$ and hydrazine hydrate in ethanol at room temperature afforded the pyimidines 48 in $61 \%$ yield. The synthesis of triazol-2-one derivative 49 could be accomplished through the interaction of the aminopyrimidine $\mathbf{4 8}$ and ethyl chloroformate, in anhydrous DMF at reflux temperature for $1 \mathrm{~h}$ and resulted in $69 \%$ yield. Treatment of compound $\mathbf{4 8}$ with carbon disulfide in an alcoholic solution of potassium hydroxide at reflux gave the triazol-2-thione, $\mathbf{5 0}$ (Scheme 15).<smiles>CCO/C=N/C1=C(C#N)C(c2ccccc2)c2c(C)cc(OC)cc2O1</smiles>

47

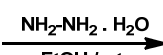
$\mathrm{EtOH} /$ r.t<smiles>Cc1cc(O)cc2c1C(c1ccccc1)c1c(ncn(N)c1=N)O2</smiles>

48 a) CICOOEt DMF-reflux $\downarrow$<smiles>[Y4][R3]=O</smiles>

Scheme 15

The condensation between the aminopyrimidine $\mathbf{4 8}$ and different carboxylic acid such as formic acid, acetic anhydride and trifluroacetic acid under reflux temperature readily, after aqueous workup, furnished the expected triazole products 51a-

While compound 48 react with cyanogen bromide in absolute ethanol containing anhydrous potassium carbonate under reflux afforded 2-amino-triazolo[1,5-c]pyrimidin-9-ol, 51d. Reaction between compound 48 and diethyl malonate was conducted in DMF under reflux conditions; elimination of water and ethanol occurred and gave the acetate derivatives 52, while condensation of compound $\mathbf{4 8}$ with methylcyano acetate in refluxing ethanol resulted in formation of the acetonitrile derivative $\mathbf{5 3}$ (Scheme 16).

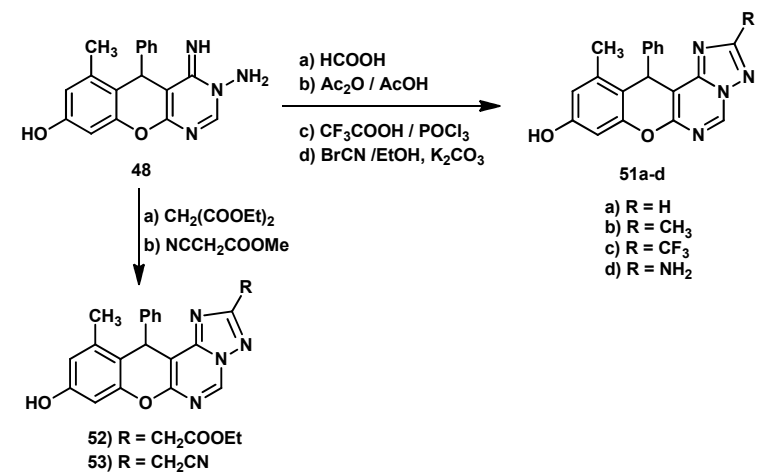

Scheme 16

Interaction between the aminopyrimidine $\mathbf{4 8}$ and benzylidene-malononitrile $\mathbf{2 d}$ in a basic medium was expected to give compound $\mathbf{5 4}$, but instead led interestingly to compound $\mathbf{5 5}$ which formed when the reactants were mixed together with few drops of acetone and left at room temperature for $30 \mathrm{~min}$. The condensation between aminopyrimidine compound $\mathbf{4 8}$ and $p$-nitrobenzaldehyde in ethanolic piperidine at reflux temperature, furnish the triazolopyrimidine $\mathbf{5 6}$ (Scheme 17).

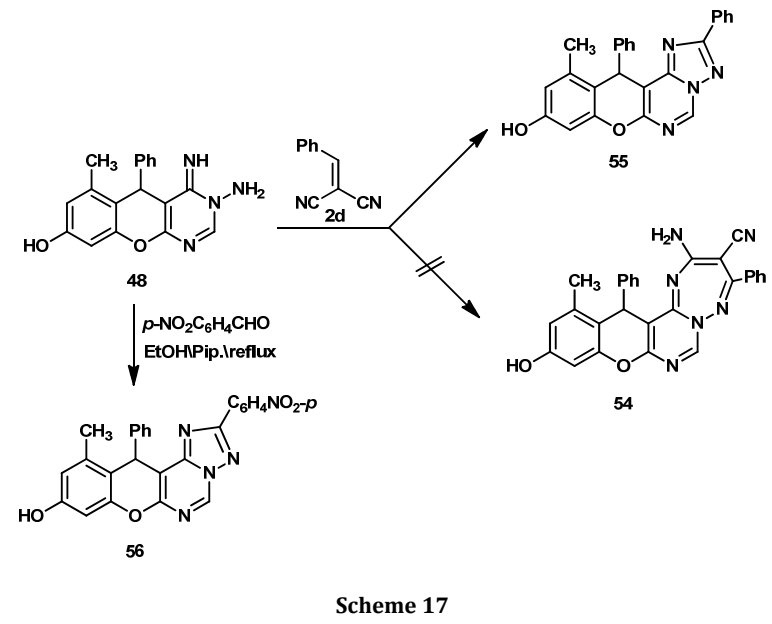

\subsection{Synthesis from 4-hydroxy coumarin [41-44]}

This synthesis involves Michael cycloaddition reaction of the readily available 4-hydroxycoumarin (57) with $\alpha$-cyano crotononitrile (2a,b and $\mathbf{e})$ in ethanolic piperidine to afforded 2-amino-3-cyano-4-( $p$-tolyl/ $p$-chlorophenyl or methyl)- $4 \mathrm{H}, 5 \mathrm{H}$ pyrano-[3,2-c][1] benzopyran-5-ones (58a-c). Treatment of 2amino-4-( $p$-tolyl $/ p$-chlorophenyl or methyl)-3-cyano- $4 \mathrm{H}, 5 \mathrm{H}$ pyrano[3,2-c][1]benzopyran-5-ones (58a-c) with triethyl ortho-formate in acetic anhydride at reflux afforded $4-(p$ tolyl/p-chlorophenyl or methyl)-3cyano-2-ethoxymethylene amino- $4 H, 5 H$-pyrano[3,2-c][1]benzo-pyran-5-ones (59a-c). Hydrazinolysis of the compound $\mathbf{5 9}$ in ethanol at room temperature yielded 9 -amino-7- $(p$-tolyl $/ p$-chlorophenyl or methyl)-8 ,9-dihydro-8-imino-6H, $7 H$-[1]benzopyrano[-3`, 4` 5,6]-pyrano[2,3-d]pyrimidine-6-ones (60a-c) (Scheme 18). Refluxing compound 60a-c with triethyl orthoformate afforded the $[1,2,4]$ triazolo[1,5-c]pyrimidines, $\mathbf{6 1 a}-\mathbf{c}$, while with acetyl chloride or chloroacetyl chloride compounds $61 \mathrm{~d}-\mathbf{f}$ and $61 \mathrm{~g}-\mathbf{i}$ were formed, respectively. Reaction of compound 60a-c with ethyl cyanoacetate and diethyl oxalate afforded the hetero cycles $61 \mathbf{j}-\mathbf{1}$ and $61 \mathrm{~m}-\mathbf{0}$, respectively, while with benzoyl chloride the 2-phenyl derivatives 61p-r was obtained (Scheme 18). 


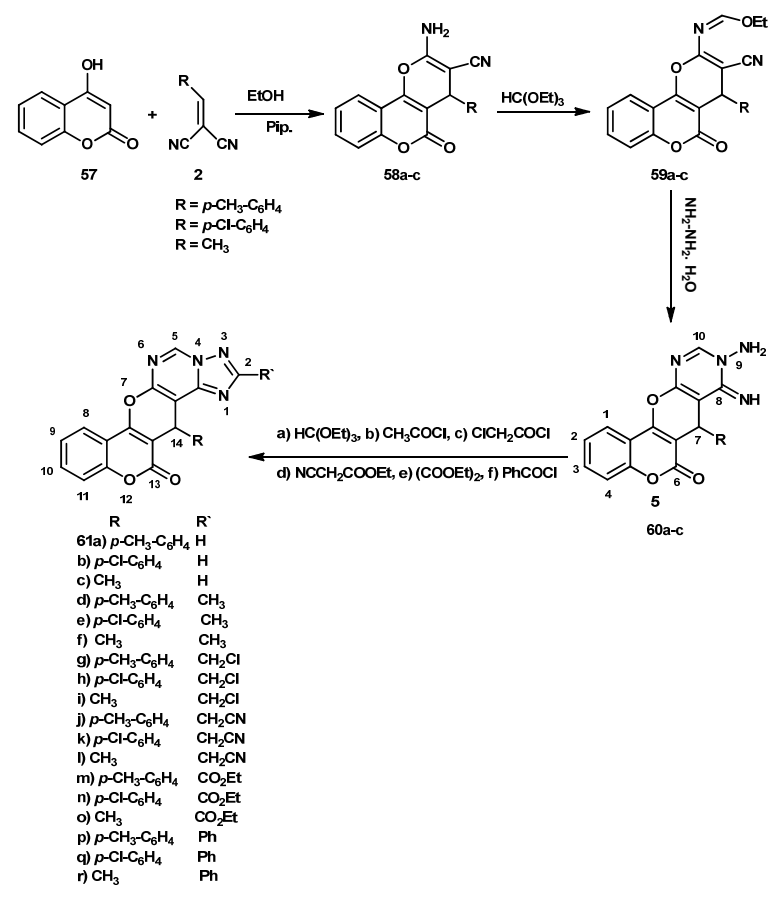

Scheme 18

The reaction of compound 60c with ethyl chloroformate, through nucleophilic displacement followed by spontaneous hydrolysis of the ester intermediate $\mathbf{6 2}$, led to the corresponding carbamic acid derivative 63, instead of compound 64 . While compound 60c was reacted with alcoholic $\mathrm{CS}_{2} /$ alc.KOH to give 14-methyl-2,3-dihydro-13-oxo- $2 H, 13 H, 14 H$-[1]benzo pyrano-[3`, 4`:5, 6]-pyrano[3, 2-e][1,2,4] triazolo [1,5-c]-pyrimidine-2-thione (65), respectively, (Scheme 19).

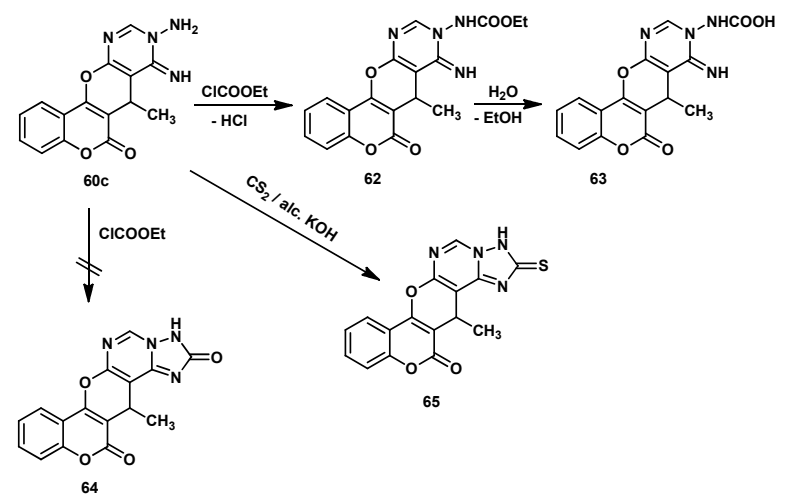

Scheme 19

When compound 60b was treated with methyl chloro formate for $30 \mathrm{~min}$, the methoxycarbonyl derivative 66 was formed, while heating of compound $\mathbf{6 0 b}$ with methyl chloroformate under reflux for $6 \mathrm{~h}$ afforded $[1,2,4]$ triazolo[1,5c]pyrimidine 67 via elimination of methanol from compound 67 (Scheme 20).

When compound $60 \mathrm{~b}$ was treated with ethyl chloroformate (2 moles) an intermediate bis(ethoxycarbonyl) derivative [G] was formed, which eliminated ethanol to furnish the ester $\mathbf{6 8}$. Treatment of compound $\mathbf{6 4}$ with carbon disulfide in alcoholic potassium hydroxide solution gave the 2-thione derivative 69 (Scheme 21).

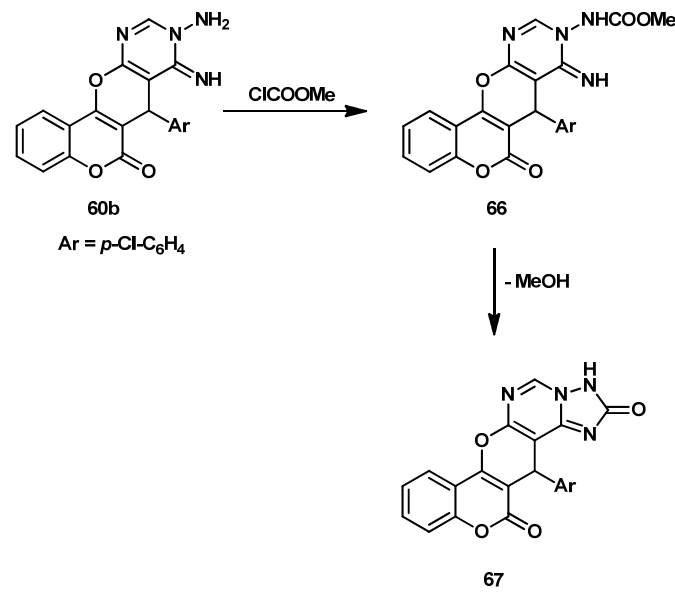

Scheme 20

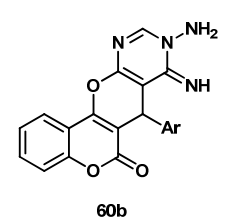

$=p-\mathrm{Cl}_{-} \mathrm{C}_{6} \mathrm{H}_{4}$<smiles>[Y9]C1c2c(c3ccccc3oc2=O)Oc2ncn3[nH]c(=S)nc3c21</smiles>

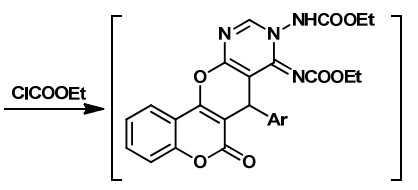

[G]

69

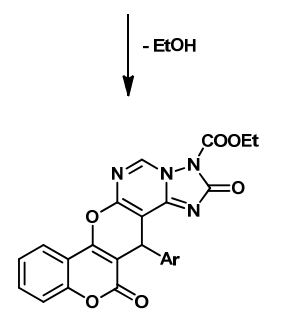

Scheme 21

\subsection{Synthesis from $\alpha$-tetralone [45]}

Synthesis of 2-amino3-cyano-5,6-dihydro-spiro[benzo $(h)$ chromene-4 $(4 H), 3^{`}(3 H)$ indol]-2 - $[1 H]$-one (73), was performed by treating of a mixture of $\alpha$-tetralone (70) with $1 \mathrm{H}$-indole-2,3dione (71) and malononitrile (72) as a ternary mixture. Heating under reflux $\mathbf{7 3}$ with triethyl orthoformate gave the corresponding ethyl methanimidate derivative $\mathbf{7 4}$. Hydrazine hydrate with compound $\mathbf{7 4}$ gave the corresponding amino imino derivatives 75. Refluxing of imino derivative $\mathbf{7 5}$ with formic or acetic acid gives the corresponding pyranotriazolo pyrimidine derivatives $\mathbf{7 6 a}, \mathbf{b}$.

Refluxing of compound $\mathbf{7 5}$ with ethyl cyanoacetate in dioxane affords the pyranotriazolopyrimidine derivative $\mathbf{7 6 c}$ (Scheme 22).

\subsection{Synthesis form 3-methyl-pyranopyrazole derivative [46]}

6-Amino-2, 4-dihydro-3-methyl-4-( $p$-nitrophenyl)pyrano [2,3-c]pyrazole-5-carbonitrile (77) $[47,48]$, as the key compound for this study and for further syntheses of other fused heterocyclic compounds, was heated at reflux temperature with an equimolar amount of triethyl orthoacetate in the presence of acetic anhydride to give a major product which could be assigned the structure of ethyl $N$-[2-acetyl-5cyano-3-methyl-4-( $p$-nitrophenyl)-2,4-dihydropyrano[2,3-c] pyrazol-6-yl] ethanimidate (78). 
When a solution of compound $\mathbf{7 8}$, in dry benzene, was stirred with hydrazine hydrate, it afforded 6-amino-3,7dimethyl-5-imino-4-( $p$-nitrophenyl)2,4,5, 6-tetrahydropyrazolo $[4,3: 5,6]$ pyrano[2,3- $d$ ] pyrimidine (79). When compound 79 was refluxed with triethyl orthoformate, it gave 5,10-dimethyl11-(p-nitrophenyl)-9,11-dihydropyrazolo $\quad\left[4^{`}, 3^{`}: 5,6\right]$ pyrano $[3$, 2 -e][1,2,4] triazolo[1,5-c] pyrimidine $(\mathbf{8 0})$. Heating of compound 79 with triethyl orthoacetate at reflux temperature, gave 2,5,10-trimethyl-11-( $p$-nitrophenyl)-9,11-dihydro-pyra zolo[4 '3`:5,6]-pyrano[3,2e][1,2,4]triazolo-[1,5-c] pyrimidine (81), respectively, (Scheme 23).
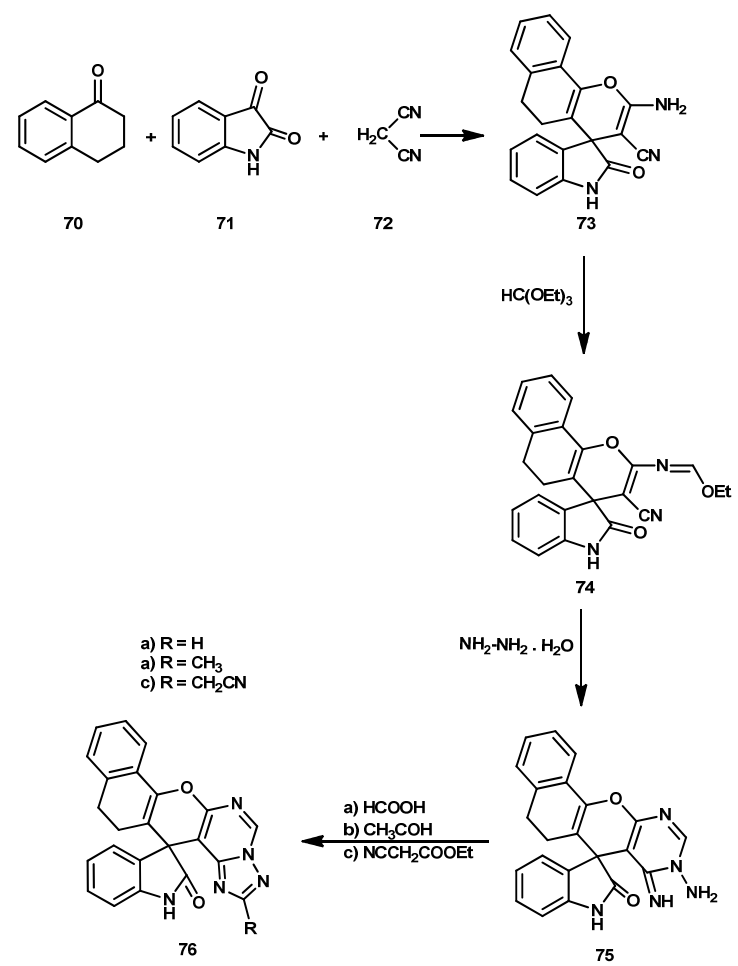

Scheme 22

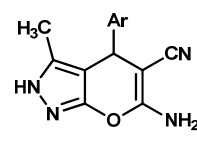

77

$\mathrm{Ar}=p-\mathrm{NO}_{2}-\mathrm{C}_{6} \mathrm{H}_{4}$
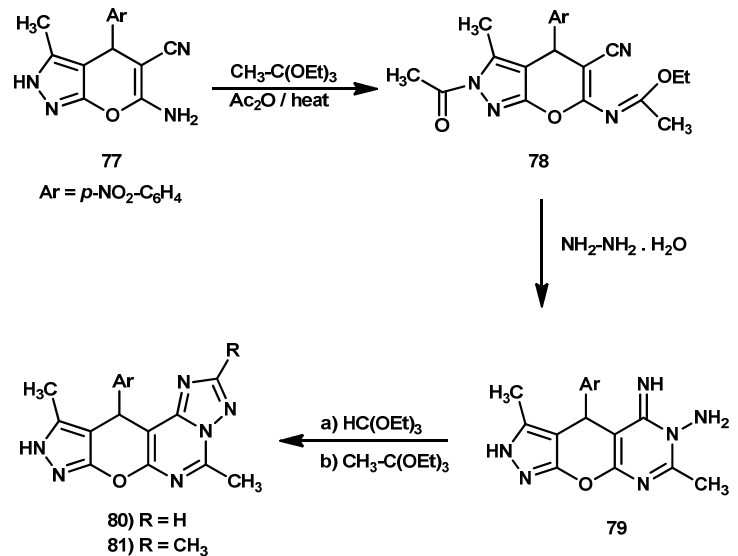

79

Scheme 23

\subsection{Synthesis from 1-phenyl-3-methyl-pyranopyrazole derivative [49]}

Reaction of 6-amino-4-(4-chlorophenyl)-1,4-dihydro-3methyl-1-phenyl-pyrano[2,3-c]pyrazole-5-carbonitrile with triethyl ortho-formate in acetic anhydride afforded methanimidate derivative (83), hydrazinolysis of compound $\mathbf{8 3}$ in methanol at room temperature afforded 1-phenyl-4- $(p$ chlorophenyl)pyrazolo[4 $\left.4^{\prime}: 5,6\right]$ pyrano[2,3,-d]pyrimidine

(84). Compound 84, considered as a key intermediate to prepare fused heterocycles as triazolo[1,5-c]pyrimidines which may possess pharmacological properties.

The cyclo-condensation of compound $\mathbf{8 4}$ with the appropriate carboxylic acid derivatives was performed by heating with an excess of neat formic acid, triethyl orthoformate or ethoxymethylene malononitrile afforded 8,11dihydro-10-methyl-8-phenyl-11-(p-chlorophenyl)[4`,3`:5,6] pyrano- $[3,2-e][1,2,4]$ triazolo[1, 5-c]pyrimidine $(\mathbf{8 5})$. When triethyl orthoacetate was used in the above cyclocondensation 3,10-dimethyl-8,11-dihydro-8-phenyl-11-(p-chlorophenyl) $[4 `, 3 ` 5,6]$-pyrano [3,2-e][1,2,4] triazolo[1,5-c]pyrimidine (86) was produced. Compound $\mathbf{8 6}$ was also produced via the reaction of compound $\mathbf{8 4}$ with acetic anhydride as carboxylic acid anhydride and acetyl chloride as acid chloride. Moreover, the interaction of triethyl orthopropionate with compound $\mathbf{8 4}$ afforded 3-ethyl-8,11-dihydro-10-methyl-8-phenyl-11-( $p$ chlorophenyl)-[4 $\left.3^{`} 3^{\prime}: 5,6\right]$ pyrano $[3,2-\mathrm{e}][1,2,4]$ triazolo $[1,5-c]$ pyrimidine (87), respectively, (Scheme 24).<smiles></smiles>

$\mathrm{Ar}=p-\mathrm{Cl}-\mathrm{C}_{6} \mathrm{H}_{4}$<smiles>NNCCO</smiles><smiles>CCCCCCn1nc(C)c2c1Oc1ncn(N)c(=N)c1C2Br</smiles><smiles>CCOC=C(C#N)C#N</smiles>

b) $\mathrm{CH}_{3} \mathrm{COCl}$ c) $\mathrm{C}_{2} \mathrm{H}_{5} \mathrm{C}(\mathrm{OEt})_{3}$ / $\mathrm{CH}_{3}-\mathrm{C}(\mathrm{OEt})_{3}$ or $\left(\mathrm{CH}_{3} \mathrm{CO}\right)_{2} \mathrm{O}$<smiles>[R]c1nc2c3c(ncn2n1)Oc1c(c(C)nn1C)C3Br</smiles>

85) $\mathrm{R}=\mathrm{H}$ 86) $\mathrm{R}=\mathrm{CH}_{3}$ 87) $\mathrm{R}=\mathrm{C}_{2} \mathrm{H}_{5}$

Scheme 24

In the case of involving the condensation of compound $\mathbf{8 4}$ with cyanogens bromide and S-methyl isothiourea sulfate, the intermediate formed might bear a cyanimino $[\mathbf{H}]$ or guanidine function [I]. These intermediates [ $\mathbf{H}$ and $\mathbf{I}]$ were cyclized in an alkaline medium to give the target molecule $\mathbf{8 8}$ as expected (Scheme 25). 

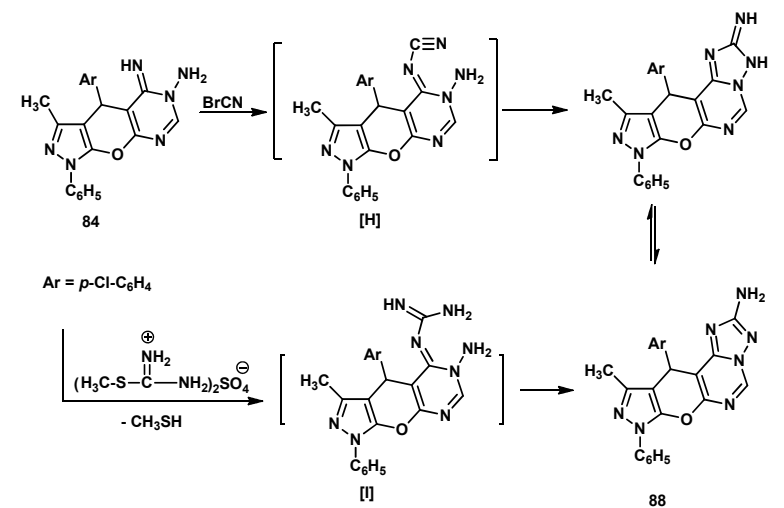

Scheme 25

The formation of 2-trichloromethyl 10-methyl-8,11dihydro-8-phenyl-11-( $p$-chlorophenyl)-[4`, 3`:5, 6]pyrano[3, 2$e][1,2,4]$ triazolo[1,5-c]- pyrimidine (90) via the interaction of compound 84 with trichloroacetic acid in the presence of phosphoryl chloride under reflux, or trichloro-acetonitrile in absence of solvent under reflux was unsuccessful. But The pyrimidinium salt 89 only isolable product (Scheme 26 ).

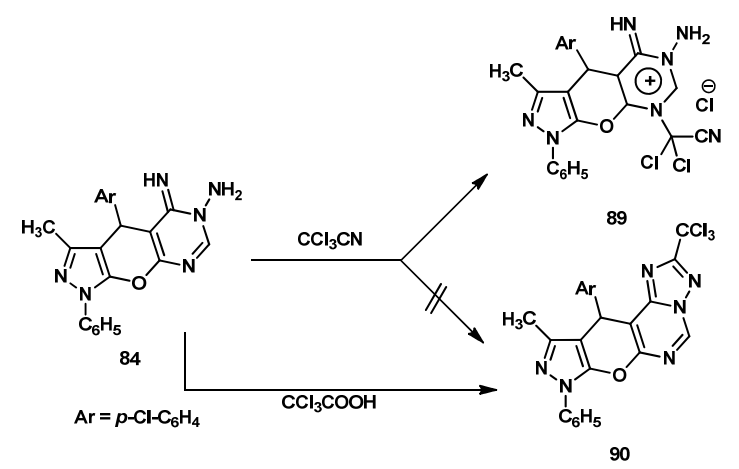

Scheme 26

The activity of compound $\mathbf{8 4}$ towards active methylene compounds, such as ethyl cyanoacetate was studied, to give 9,12-dihydro-3-hydroxyl-11-methyl-8-phenyl-12-( $p$-chloro phenyl)-2H-pyrazolo[4 $\left.33^{`}: 5,6\right]$ pyrano-[2`,3`5,6]pyrimido[1,6b] $[1,2,4]$ triazine $(\mathbf{9 1})$, but non-isolable triazolopyrimidine 92 (Scheme 27).

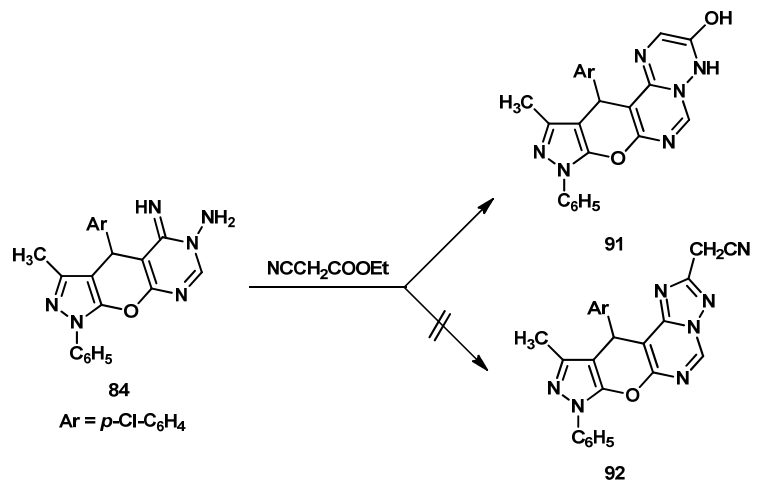

Scheme 27

Compound 84, when reacted with $\beta$-cyanocinnamonitrile derivatives, namly $p$-toylmalononitrile and $p$-anisylmalono nitrile respectively, in dioxane under reflux and in the presence of a catalytic amount of piperidine failed to afford pyrano triazolopyrimidine derivatives $\mathbf{9 4}$ and pyranopyrimidine derivatives 93a,b, were isolable products, via the formation of 1:1 adduct followed by the loss of malononitrile. Also the same product 93a,b was isolate from the reaction of compound $\mathbf{8 4}$ with $p$-tolulaldehyde and $p$-anisaldehyde, respectively, (Scheme 28).

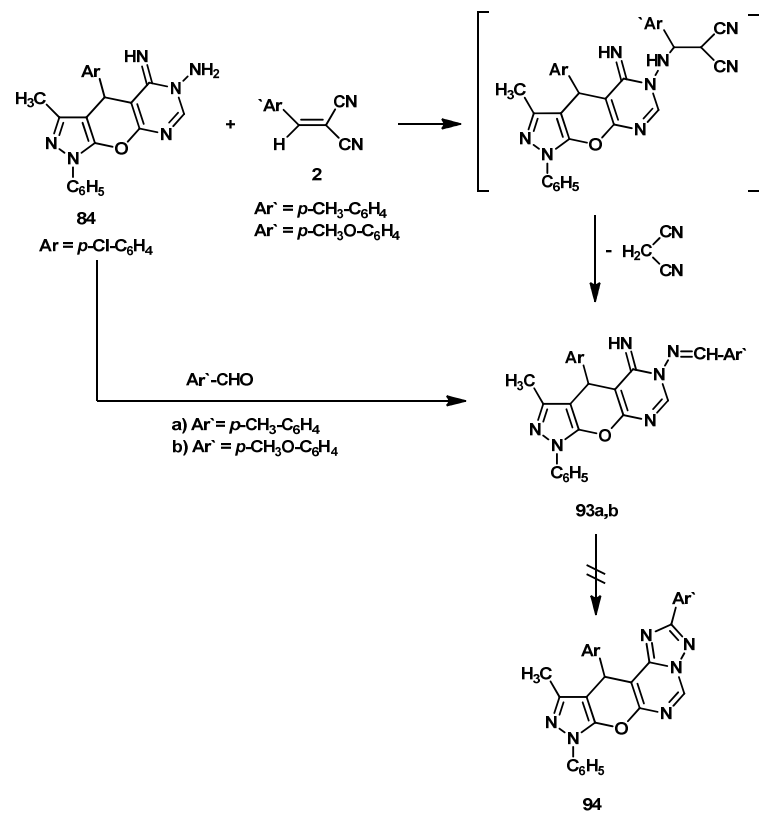

Scheme 28

\subsection{Synthesis from spirooxindolopyran [50]}

The reaction of spirooxindolopyran 95 with an excess of orthoformic ester leads to the ethoxymethyleneaminonitrile 96, which enters into cascade heterocyclization with benzo hydrazide and subsequent closure of the pyrimidine and triazole rings, leading to a high yield of 2'-oxo-2-phenyl-1', 2', 5, 6, 7, 8-hexahydrospiro[1-benzopyrano[3, 2-e][1, 2, 4]triazolo [1,5-c]pyrimidine-2,3'-[3H]indole] (97), respectively, (Scheme 29).

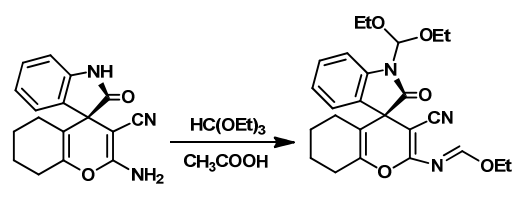

95

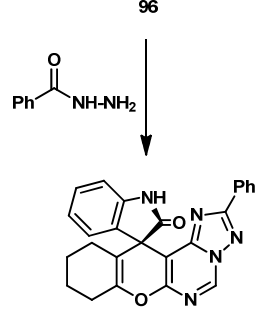

97

Scheme 29

\subsection{Synthesis from 8-hydroxy-2-methylquinoline [51,52]}

Condensation of 8-hydroxy-2-methylquinoline (98) with $p$ chloro-benzaldehyde in acetic anhydride under reflux or microwave irradiation afforded (E)-2-(4-chlorostyryl)-8hydroxyquinoline (99). 

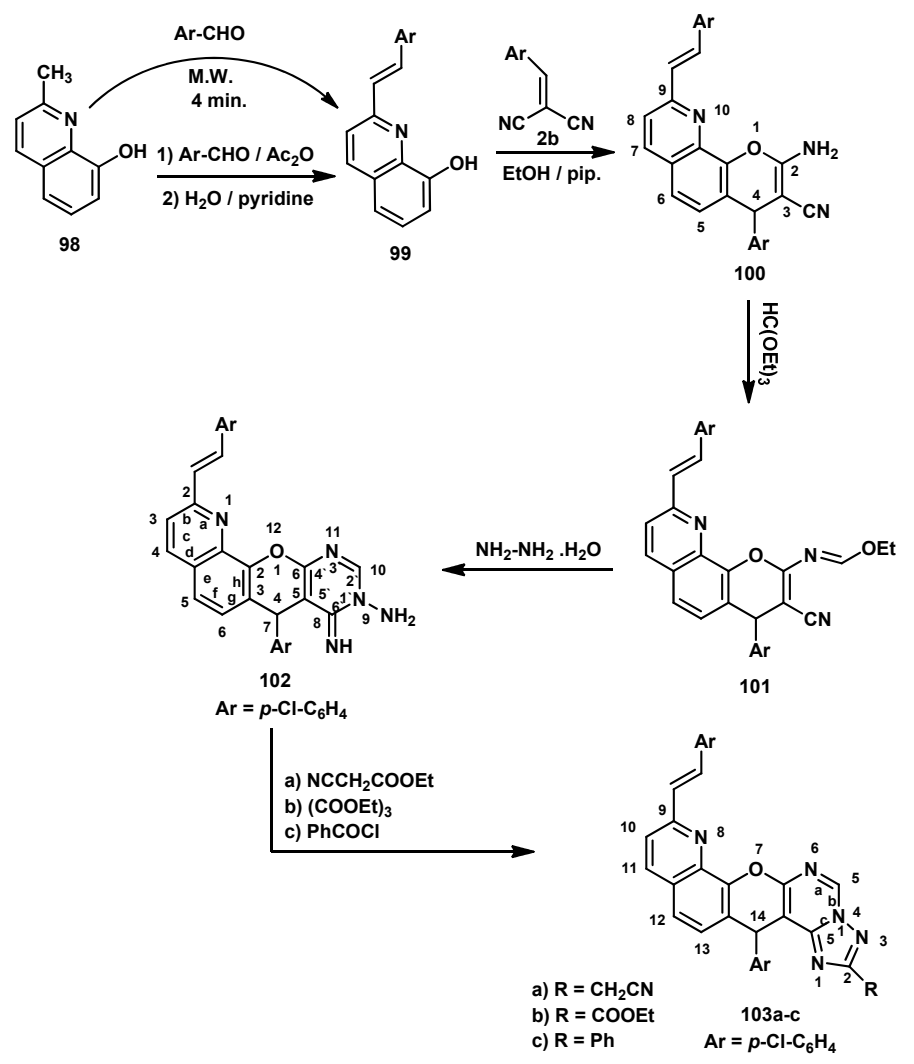

Scheme 30

The reaction of $(E)$-2-(4-chlorostyryl)-8-hydroxyquinoline (99) with $\alpha$-cyano- $p$-chloro-cinnamonitrile $(\mathbf{2 b})$ in ethanolic piperidine under reflux afforded (E)-2-amino-4-(4chlorophenyl)-9-(4-chlorostyryl)-4H-pyrano[3,2-h]-quino line3 -carbonitrile (100). Compound $\mathbf{1 0 0}$ was subjected for further reactions to produce fused heterotetracyclic or hetero pentacyclic systems incorporating pyrimidine or pyrimido $[1,2,4]$ triazolo nuclei in addition to pyranoquinoline moiety. Treatment of compound $\mathbf{1 0 0}$ with triethyl orthoformate in acetic anhydride at reflux gave the corresponding $(E)$-2-ethoxy methyleneamino-4-(4-chlorophenyl)-9-(4-chlorostyryl)-4Hpyrano[3,2-h]quinoline-3-carbonitrile $(\mathbf{1 0 1})$, while reaction with hydrazine hydrate gave the cyclic addition product $(E)-9$ amino-7-(4-chlorophenyl)-2-(4-chlorostyryl)-8-imino-8,9-di hydro-7H-pyrimido[4',5': $\quad 6,5]$ pyrano[3,2-h]quinoline $\quad(\mathbf{1 0 2})$ (Scheme 30).

The imino compound 102 proved to be a useful intermediate for the synthesis of a variety of 2 -substituted$14 H$-pyrimido[4', 5' : 6, 5]pyrano-[3, 2-h][1, 2, 4]triazolo[1, 5c] quinoline derivatives. Thus, treatment of compound $\mathbf{1 0 2}$ with ethyl cyanoacetate and with diethyl oxalate in refluxing absolute ethanol afforded 14-(4-chlorophenyl)-9-(4-chloro tyryl)-2-cyanomethyl-14H-pyrimido[4', 5':6, 5]pyrano[3, 2- $h]$ $[1,2,4]$ triazolo[1,5-c]quinoline (103a) and ethyl 14-(4-chloro phenyl)-9-(4-chlorotyryl)-14H-pyrimido[4', 5':6, 5]pyrano[3, 2$h][1,2,4]$ triazolo[1,5-c]-quinoline-2-carboxylate $(\mathbf{1 0 3} \mathbf{b})$, respectively. Arylation of compound $\mathbf{1 0 2}$ with benzoyl chloride in refluxing dry benzene proceeded readily to give the 2-phenyl derivative 103c, respectively, (Scheme 30).

\subsection{Synthesis from $3-\mathrm{N}, \mathrm{N}$-diethylaminophenol $[53,54]$}

Treatment of 3-N,N-diethylaminophenol (104) with various substituted $\alpha$-cyanocinnamonitriles $(\mathbf{2 b}, \mathbf{c})$ in ethanol and piperidine afforded 2-amino 4-(4-chloro/bromophenyl)-7(diethylamino)-coumarin-3-carbonitrile $(\mathbf{1 0 5 a}, \mathbf{b})$. Treatment of 105a,b with triethyl ortho-formate in acetic anhydride at reflux gave the corresponding 4-(4-chloro/bromophenyl)-7(diethylamino)-2-ethoxymethyleneamino- $4 \mathrm{H}$-chromene-3carbonitrile $(\mathbf{1 0 6} \mathbf{a}, \mathbf{b})$. Hydrazinolysis of compound 106a in ethanol at room temperature afforded.

The aminoimino derivatives 3-amino-5-(4-chloro/bromo phenyl)-8-(diethylamino)-4-imino-3,4-dihydro-5 $\mathrm{H}$-chromeno [2,3-d]pyrimidine (107). Reactions of compound 107 with carboxylic acid derivatives afforded triazolopyrimidine derivatives 108 . When compound 107 was treated with methyl chloroformate afforded 2-oxo-triazolopyrimidine 109 via elimination of methanol. While treatment compound 107 with ethyl chloroformate an eliminated ethanol to furnish the ester 110 (Scheme 31)

\subsection{Synthesis from 5, 5-dimethyl-1,3-cyclohexanedione [55]}

One pot multicomponent, condensation reaction of $p$ chlorobenzaldehyde or 3,4,5 trimethoxy benzaldehyde, malono nitrile and 5,5-dimethyl-1,3-cyclohexanedione (111) in ethanol and piperidine afforded $4 H$-chromeno-3-carbonitrile (112). Treatment of compound $\mathbf{1 1 2}$ with triethyl orthoformate in acetic anhydride at reflux gave the corresponding ethoxy methyleneamino- $4 H$-chromene-3-carbonitrile, 113. Hydrazinolysis of compound $\mathbf{1 1 3}$ in ethanol at room temperature afforded the aminoimino derivatives 114. Reactions of compound 114 with triethyl orthoformate, acetic anhydride, and $p$-chlorobenzaldehyde in pyridine afforded triazolopyrimidine derivatives 115 (Scheme 32). 


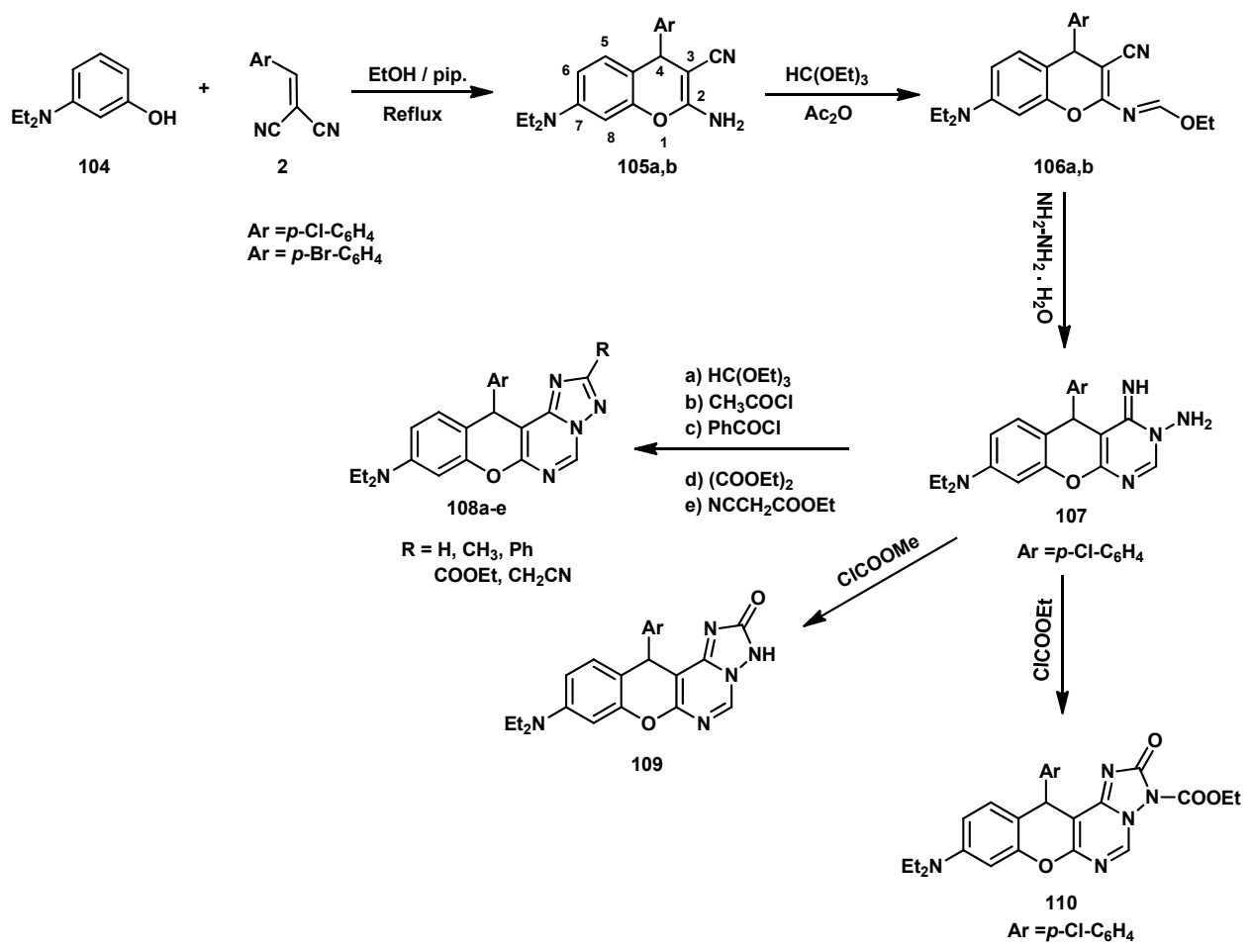

Scheme 31

${ }_{0}^{11}$

111
$+\mathrm{CH}_{2}(\mathrm{CN})_{2}+\mathrm{Ar}-\mathrm{CHO}$

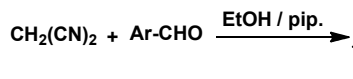

$\mathrm{Ar}=p-\mathrm{Cl}-\mathrm{C}_{6} \mathrm{H}_{4}$ $\mathrm{Ar}=3,4,5(\mathrm{OMe})_{3}-\mathrm{C}_{6} \mathrm{H}_{2}$

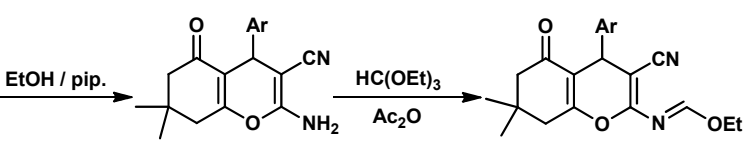

112

113<smiles>[R]c1nc2c3c(ncn2n1)OC1=C(C(=O)CC(C)(C)C1)C3Br</smiles>

115

$$
\text { a) } \mathrm{HC}(\mathrm{OEt})_{3}
$$
b) $\mathrm{Ac}_{2} \mathrm{O} / \mathrm{AcOH}$

$\mathrm{Ar}=p-\mathrm{Cl}-\mathrm{C}_{6} \mathrm{H}_{4}$

$\mathrm{R}=\mathrm{H}, \mathrm{CH}_{3}, \mathrm{p}-\mathrm{Cl}-\mathrm{C}_{6} \mathrm{H}_{4}$

$\mathrm{Ar}=p-\mathrm{Cl}-\mathrm{C}_{6} \mathrm{H}_{4}$

Scheme 32

\section{Reactions of pyranotriazolopyrimidines with}

\subsection{Phenolic aldehydes [25,56]}

Reaction of 11-methoxy-14-( $p$-tolyl)-14H-naphtho[2,1$b]$ pyrano[3,2-e][1, 2, 3] triazol[1,5-c]pyrimidine-2-ethanenitrile (6d) with phenolic aldehydes such as salicylaldehyde and or 2hydroxy-1-naphthaldehyde in dioxane refluxed for $3 \mathrm{~h}$, afforded the corresponding 2-(coumarin-3-yl)-11-methoy-14( $p$-tolyl)-14H-naphtho[2,1-b]pyrano[3, 2-e][1,2,4]triazolo-[1, 5$c$ pyrimidine (116) and 2-(benzo-5:6-coumarin-3-yl)-11methoy-14-( $p$-tolyl)-14H-naphtho[2, 1-b]pyrano[3, 2-e][1, 2, 4] triazolo[1,5-c]pyrimidine (117), respectively (Scheme 33).

\subsection{Trialkyl phosphite [57]}

Synthesis a series of $\alpha$-functionalized imino ethers $\mathbf{2 6}$ and 118 have subjected them to reaction with aqueous solution of hydrazine in methanol at $0{ }^{\circ} \mathrm{C}$ to give the naphthopyrano triazolopyrimidines 119. The key intermediate, 2-chloro methyl-naphthopyranotriazolopyrimidines $\mathbf{1 2 0}$, was prepared according to the literature procedure ${ }^{31}$, through a cyclization reaction of binucleophiles $\mathbf{1 1 9}$ using chloroacetyl chloride.

The formation of naphthopyranotriazolopyrimidines phosphornate 121, in good yield was carried out via MichaelisArbuzov rearrangement (Arbusov reaction) of naphthopyrano triazolopyrimidines chloride $\mathbf{1 2 0}$ with trialkyl phosphate (Scheme 34). 


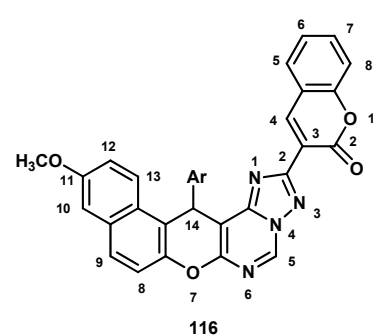

(c)<smiles>COc1cccc(C2c3ccc(OC)cc3C=Cc3oc4ncn5nc(-c6cc7c(ccc8ccccc87)oc6=O)nc5c4c32)c1</smiles>

Scheme 33

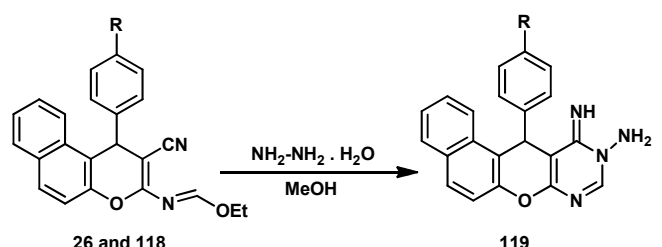

$\mathrm{R}=\mathrm{H}, \mathrm{Et}, \mathrm{MeO},-\mathrm{PPr}, \mathrm{Cl}$

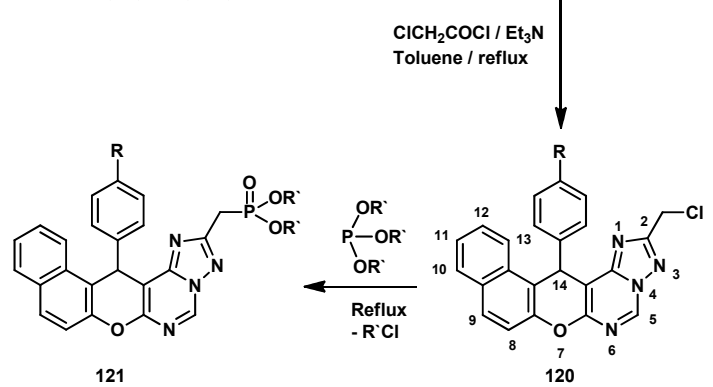

12

120

$\mathrm{R}=\mathrm{H}, \mathrm{Et}, \mathrm{MeO},-\mathrm{iPr}, \mathrm{Cl}$

$\mathrm{R}^{\prime}=\mathrm{CH}_{3}, \mathrm{Et}$

Scheme 34

\section{Applications of pyrano triazolo pyrimidines}

The chemistry of pyran and fused pyran derivatives has attracted many researchers due to their biological activities and their potential applications as pharmacological agents. Several derivatives of the pyran exhibit antimicrobial activity $[29,53,58]$, growth stimulating effects [59], antifungal and plant growth regulation effects [60], antitumor activity [61], central nervous system (CNS) activity [62] and hypotensive effect [63]. Moreover pyran derivatives are well known for antihistaminic activity [64], platelet anti-aggregating activity and local anaesthetic activity [65-67], antiallergenic effect [68], antidepressant effect [69] and as anti-proliferation agents [70,71]

\subsection{Potent antibacterial activities}

Potent antibacterial activities [25-27,30,32,46,53,54] were found naphthopyranotriazolopyrimidine derivatives $(\mathbf{6 , 1 4 , 2 1}$ and 27), pyrazolopyranotriazolopyrimidines (81) and chrome notriazolopyrimidines (108-110) (Scheme 35).

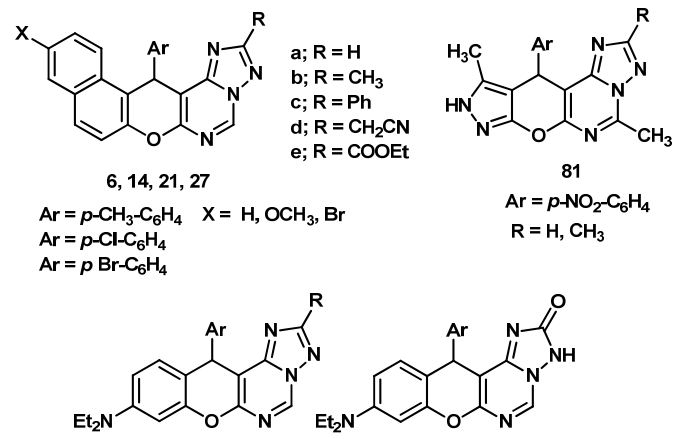

108

109

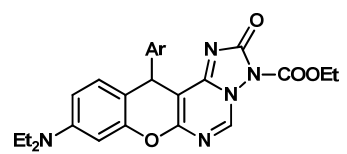

110

Scheme 35

\subsection{Antitumor activities}

Chromenotriazolopyrimidines (41-46) and pyrimido pyranotriazolo-quinolines $(\mathbf{1 0 3}, \mathbf{1 2 2})$ have antitumor (Scheme 36) $[39,51,52,72]$.
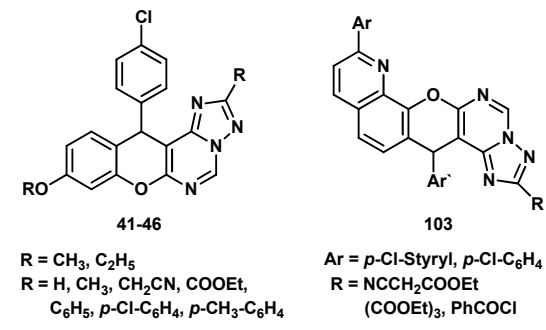

$\mathrm{Ar}=p-\mathrm{Cl}-\mathrm{Styryl}, p-\mathrm{Cl}-\mathrm{C}_{6} \mathrm{H}_{4}$ $\mathrm{R}=\mathrm{NCCH}_{2} \mathrm{COOE}$ $(\mathrm{COOEt})_{3}, \mathrm{PhCOCI}$<smiles>[R3]c1ccc(-c2nc3c4c(ncn3n2)C(c2ccccc2)c2c(C)cc(O)cc2O4)c([R])c1[R]</smiles>

$$
\begin{array}{c|l|l|l|}
\text { 122a-d } & \mathrm{R}_{1} & \mathrm{R}_{2} & \mathrm{R}_{3} \\
\hline \mathrm{a} & \mathrm{H} & \mathrm{H} & \mathrm{Cl} \\
\mathrm{b} & \mathrm{Cl} & \mathrm{H} & \mathrm{H} \\
\mathrm{c} & \mathrm{Cl} & \mathrm{H} & \mathrm{Cl} \\
\mathrm{d} & \mathrm{H} & \mathrm{NO}_{2} & \mathrm{H}
\end{array}
$$

Scheme 36 


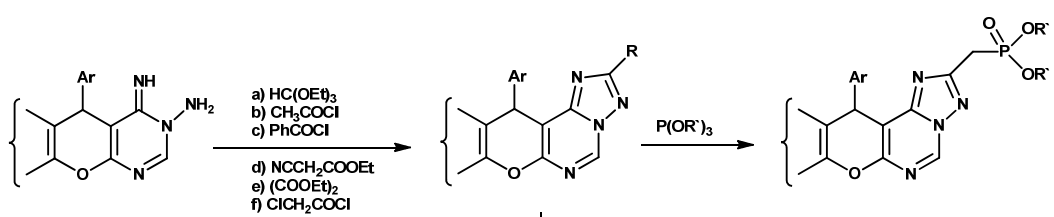<smiles></smiles>

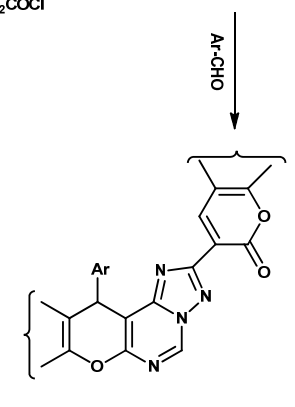

Scheme 40

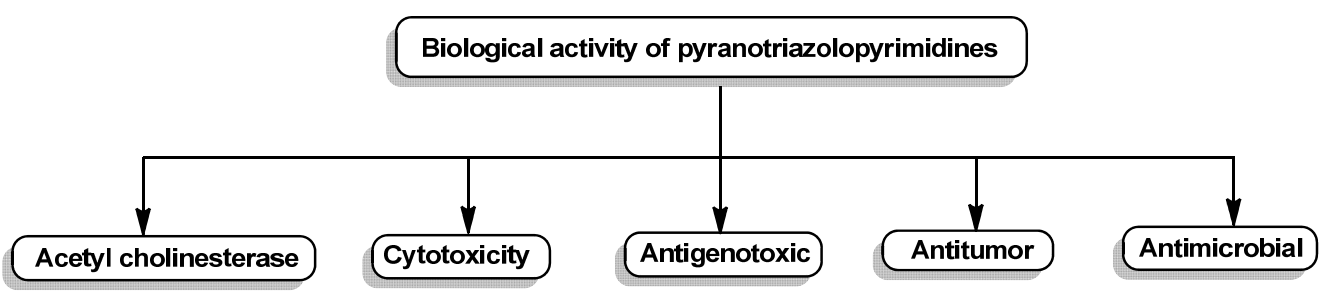

Figure 2. Biological activity of pyranotriazolopyrimidines.

\subsection{Anti-genotoxic activities}

Naphthopyranotriazolopyrimidine derivatives (27a-g) have anti-genotoxic activity (Scheme 37) [32].
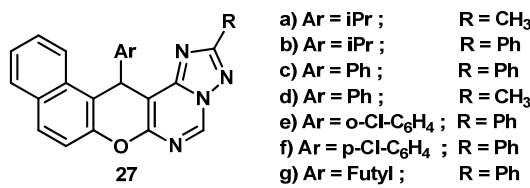

Scheme 37

\subsection{Cytoxicity activities}

Chromenotriazolopyrimidines (108-110) have cytoxicity activities (Scheme 38) [54].

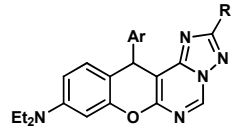

108<smiles></smiles>

110

Scheme 38

\subsection{Acetyl cholinesterase inhibition}

Naphthopyranotriazolopyrimidine derivatives (123) have acetyl cholinesterase, also known as AChE or acetylhydrolase inhibition (Scheme 39) [73].

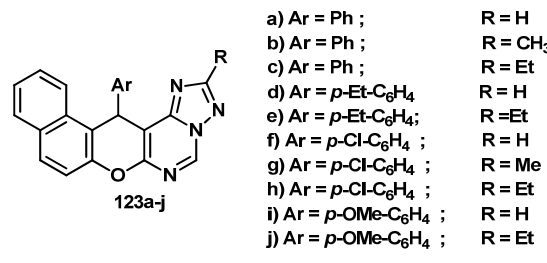

Scheme 39

\section{Conclusions}

The present review has outlined the synthesis of pyranotriazolo-pyrimidine derivatives by using key intermediate aminoimino pyranopyrimidines and appropriate carboxylic acid derivatives (Scheme 40). Reaction of 2-aceto nitrile pyrano triazolo pyrimidines with phenolic aldehydes afforded coumarin derivatives. Also reaction of 2-chloromethyl-naphthopyranotriazolopyrimidines with trialkyl phosphite afforded naphthopyranotriazolopyrimidine dialkyl phosphonates. Pyranotriazolopyrimidine derivatives have been reported to furnish interesting biological properties (Figure 2).

\section{Acknowledgements}

The support of the Jazan University of Jazan, Saudi Arabia and Al-Azhar University, Cairo, Egypt. We thanks Prof. Dr. Ahmed Hammam Bedair, Organic chemistry of Chemistry Department, Faculty of Science, Al-Azhar University

\section{References}

[1]. Bloxham, J.; Dell, C. P.; Smith, C. W. Heterocycles 1994, 38, 339-408.

[2]. Nawawar, G. A.; Abdelrazek, F. M.; Swellam, R. H. Arch. Pharm. 1991 342, 875-877.

[3]. Zamocka, J.; Misikova, E.; Durinida, J. Pharmazie 1991, 46, 610-613. 
[4]. Hong, J. W.; Xiao, Q. R.; Yan, Y. Z; Zhan, H. Z. J. Braz. Chem. Soc. 2009, 20, 1939-1943.

[5]. Saman, D.; Reza, S.; Majid, V.; Hamid, R. M. Chinese Chem. Lett. 2012, $23,253-256$.

[6]. Hossein, E.; Gholam, H. Z.; Reza, S.; Saman, D. Heterocycl. Commun. 2012, 18(2), 67-70.

[7]. Mogilaiah, K.; Sharath, B. H.; Vidya, K.; Shiva, K. K. Indian J. Chem. B 2010, 49, 390-393.

[8]. Wang, X. S.; Yang, G. S.; Zhao, G. Tetrahedron Asymmetr. 2008, 19, 709714.

[9]. Itokawa, H.; Mihar, T.; Takeya, K. Chem. Pharm. Bull. 1983, 31, 23532358.

[10]. Martinez, A. G.; Marco, L. J. Bioorg. Med. Chem. Lett. 1997, 7, 31653170.

[11]. Dell, C. P.; Smith, C. W. Eur. Pat. 537, 94, 9 21Apr 1993; ref. Chem. Abstr. 1993, 119, 139102d.

[12]. Bianchi, G.; Tava, A. Agric. Biol. Chem. 1987, 51, 2001-2002.

[13]. Marec, F.; Kollarova, I.; Jegorov, A. Planta Med. 2001, 67, 127-131.

[14]. Gil, S. J.; Dong, S. L.; Dong, C K. .; Yurngdong, J.; Jong, K. S.; Seung, H. L; Youn, C. K. Eur. J. Pharmacol. 2011, 654, 226-234.

[15]. Fischer, G. Adv. Heterocycl. Chem. 1993, 57, 81-138.

[16]. Shaban, M. A. E.; Morgan, A. E. A. Adv. Heterocycl. Chem. 2000, 77, 345394.

[17]. Shaban, M. A. E.; Morgan, A. E. A. Adv. Heterocycl. Chem. 2000, 73, 131176.

[18]. Shaban, M. A. E.; Morgan, A. E. A. Adv. Heterocycl. Chem. 2000, 75, $243-$ 281.

[19]. Zhang, N.; Ayral-Kaloustian, S.; Nguyen, T.; Afragola, J.; Hernandez, R.; Lucas, J.; Gibbons, J.; Beyer, C. J. Med. Chem. 2007, 50, 319-327

[20]. Havlicek, L.; Fuksova, K.; Krystof, V.; Orsag, M.; Vojtesek, B.; Strnad, M. Bioorg. Med. Chem. 2005, 13, 5399-5403.

[21]. Fraley, M. E.; Hoffman W. F.; Rubino R. S. Bioorg. Med. Chem. Lett. 2002, 12, 2767-2770.

[22]. Chen, Q.; Zhu, X. L.; Jiang, L. L.; Liu, Z. M.; Yang, G. F. Eur. J. Med. Chem. 2008, 43, 595-603.

[23]. Shigeko, U.; Shinya, T.; Takako, M.; Tomiichiro, O. Brain Res. 2002, 946, 298-306.

[24]. Abdel-Rahman, H. M.; El-Koussi, N. A.; Hassan, H. Y. Arch Pharm. 2009, 342(2), 94-99.

[25]. Fathy, A. E.; Ashraf, H. F.; Gameel, A. M. E.; Mostafa, M. K. Acta Pharm. 2004, 54, 13-26.

[26]. Ashraf, H. F. A. Pharmaceuticals 2012, 5, 745-757.

[27]. Ashraf, H. F. A. J. Al-Azhar Bull. Sci. 2012, 1, 13-27.

[28]. Ahmed, Z. S.; Nagwa, A. E.; Ahmed, M. E. J. Chem. Res. 2000, 164-166.

[29]. Ahmed, H. B.; Hussien, A. E.; Nagwa, A. E.; Kamal, A. R.; Ahmed, M. E. Il Farmaco 2001, 56, 968-973.

[30]. El-Agrody, A. M.; El-Hakim, M. H.; Abd El-Latif, M. S.; Fakery, A. H.; ElSayed, E. M.; El-Ghareab, K. A. Acta Pharm. 2000, 50, 111-120

[31]. Kamar, M.; Fakher, C.; Abdelouahid, S.; Jose, M. C.; Mansour, S. Heteroletters. Org. 2011, 1, 95-105.

[32]. Fakher, C.; Mehdi, M.; Hedi, B. M.; Leila, C. G.; Mansour, S. Eur. J. Med. Chem. 2007, 42, 715-718.

[33]. Giudice, M. R. D.; Borioni, A.; Gatta, F. J. Heterocycl. Chem. 1994, 13, 1503-1507.

[34]. Zaki, M. E. A.; Fawzy, N. M.; Swelam, S. A. Molecules 1999, 3, 1-8.

[35]. Hafidh, A.; Baccar, B. J. Soc. Alg. Chim. 2002, 12, 89-97.

[36]. Zuming, L.; Guangfu, Y.; Xianghua, Q. J. Chem. Technol. Biotechnol. 2001, 76, 1154-115.8

[37]. Messaad, M.; Chabchoub, F.; Salem, M. Heterocycl. Commun, 2005, 11, 139-144.

[38]. El-Agrody, A. M.; Emam, H. A.; El-Hakim, M. H.; Abd El-Latif, M. S.; Fakery, A. H. J. Chem. Res. (S) 1997, 320-321.

[39]. Manal, M. K.; Aliaa, M. K.; Eman, K. A.; Heba A. H. Eur. J. Med. Chem. 2013, 59, 183-193.

[40]. Mohammed, F. K.; Badrey, M. G. J. Korean Chem. Soc. 2011, 55(2), 218229.

[41]. El-Agrody, M. A.; Abd El-Latif, S. M.; Fakery, H. A.; Bedair, H.; A. J. Chem. Res. 2000, 26-27.

[42]. Bedair, H.; A.; El-Hady, A. N.; Abd El-Latif, S. M.; Fakery, H. A.; ElAgrody, M. A. Il Farmaco 2000, 55, 708-714.

[43]. El-Hady, A. N.; El-Agrody M. A.; Abd El-Latif, S. M.; Fakery, H. A.; Bedair, H. A. Molecules 2001, 6, 519-521.

[44]. Ashraf, H. F. A. Acta Pham. 2003, 58, 701-720.

[45]. Aly, H. A.; Ibraheim, I. A.; El-Saied H. E.; Nashwa, M. M. Oriental J. Chem. 2008, 24(3), 801-806.

[46]. Ahmed, H. S.; Magdi, E. A. Z; Eman, M. H. M.; Faiza M. A.;Farouk, M. E. A. Arch. Pharm. Chem. Life Sci. 2007, 340, 345-351.

[47]. Magdi, E. A. Z.; Eman, M. H. M.; Faiza, M. A. Heterocycl. Comm. 2004, 10, 97-102.

[48]. Ahmed, H. S.; Magdi, E. A. Z; Eman, M. H. M.; Faiza, M. A.; Farouk, M. E. A. Arch. Pharm. 2007, 340, 236-243.

[49]. Zaki, M. E. A. Molecules 1998, 3, 71-79.

[50]. Kurbatov, E. S.; Starikova, Z. A.; Krasnikov, V. V.; Mezheritskii, V. V. Chem. Heterocyc. Compd. 2006, 42 (10), 1366-1367.
[51]. Musial, R.; Jampilek, J.; Buchta, V.; Silva, L.; Niedbala, H.; Podezwa, B.; Palka, A.; Majerz, M. K.; Oleksyn, B.; Polansk, J. Bioorg Med. Chem. 2006, 14, 3592-3598

[52]. Abdullah, M. A.; Ashraf, H. F. A.; Hany, M. M; Ahmed, M. E. Lett. Drug Des. Discov. 2012, 9, 459-470.

[53]. Nermien, N. S.; Hany, M. M.; Esaam, S. A.; Shymaa, S. A.; Ahmed, M. E. Eur. J. Med. Chem. 2011, 46, 765-772.

[54]. El-Agrody, A. M.; Sabry, N. M.; Motlaq, S. S. J. Chem. Res. 2011, 2, 77-83.

[55]. Hassanien, A. A.; Zahran, M. A.; El-gaby, M. S. A.; Ghorab, M. M. J. Indian Chem. Soc. 1999, 76(7), 350-354.

[56]. Ben, S. A.; Romdhane, A.; Elie, N.; Touboul, D.; Ben, H. Lett. Org. Chem. 2013, 10(3), 185-190.

[57]. Anis, R.; Jean, F. G.; Mhamed, A. H.; Hichem, B. J. Phosphorus Sulfur 2012, 187, 612-618.

[58]. Georgiadis, M. p.; Cauladouros, E. A.; Delitheos, A. K. J. Pharm. Sci. $1992,81,1126-1131$.

[59]. Zamocka, J.; Misikova, E.; J. Durinda, J. Cesk. Slov. Farm. 1992, 41, 170172.

[60]. Ohira, T.; Yatagai, M. J. Jpn. Wood Res. Soc. 1993, 39, 237-242

[61]. Mohr, S. J.; Chirigos, M. A.; Fuhrman, F. S.; Pryor, J. W. Cancer Res. 1975, 35, 3750-3754.

[62]. Eiden, F.; Denk, F. Arch Pharm. Weinheim Ger. (Arch. Pharm.) 1991 324, 353-354

[63]. Tandon, V. K.; Vaish, M.; Jain, S.; Bhakuni, D. S.; R. C. Srimal, R. C. Indian J. Pharm. Sci. 1991, 53, 22-23.

[64]. Bargagna, A.; Longobardi, M.; Mariani, E.; Schenone, P.; Marmo, E. Farmaco 1990, 45, 405-413.

[65]. Bargagna, A.; Longobardi, M.; Mariani, E.; Schenone, P.; Marmo, E. Farmaco 1991, 46, 461-475.

[66]. Bargagna, A.; Longobardi, M.; Mariani, E.; Schenone, P.; Marmo, E. Farmaco 1992, 47, 345-355.

[67]. Gorlitzer, K.; Dehre, A.; Engler, E. Arch Pharm. Weinheim Ger. (Arch Pharm.) 1983, 316, 264-270.

[68]. Ermili, A.; Roma, G.; Buonamici, M.; Cuttica, A.; Galante, M. Farmaco Ed. Sci. 1979, 34, 535-544.

[69]. Dell, C. P.; Smith, C. W. European Patent Appl. EP 537949, Chem. Abstr. 119 (1993) 139102d

[70]. Brunavs, M.; Dell, C. P.; Gallagher, P. T.; Owton, W. M.; Smith, C. W. European Patent Appl. EP 557075. Chem. Abstr. 120 (1994) 106768t.

[71]. Mohamed, G. B.; Sobhi M. G. Molecules 2012, 17, 11538-11553.

[72]. Anis, R.; Marie, T. M.; Abderrahim, B. S.; Aymen, J.; Hichem, B. J. J. Soc. Chim. Tunisie 2012, 14, 1277-1280. 